\title{
Anopheles metabolic proteins in malaria transmission, prevention and control: a review
}

\author{
Eunice Oluwatobiloba Adedeji 1,2, Olubanke Olujoke Ogunlana ${ }^{1,2}$, Segun Fatumo ${ }^{3}$, Thomas Beder ${ }^{4}$, \\ Yvonne Ajamma', Rainer Koenig ${ }^{4^{*}}$ and Ezekiel Adebiyi ${ }^{1,5,6^{*}}$
}

\begin{abstract}
The increasing resistance to currently available insecticides in the malaria vector, Anopheles mosquitoes, hampers their use as an effective vector control strategy for the prevention of malaria transmission. Therefore, there is need for new insecticides and/or alternative vector control strategies, the development of which relies on the identification of possible targets in Anopheles. Some known and promising targets for the prevention or control of malaria transmission exist among Anopheles metabolic proteins. This review aims to elucidate the current and potential contribution of Anopheles metabolic proteins to malaria transmission and control. Highlighted are the roles of metabolic proteins as insecticide targets, in blood digestion and immune response as well as their contribution to insecticide resistance and Plasmodium parasite development. Furthermore, strategies by which these metabolic proteins can be utilized for vector control are described. Inhibitors of Anopheles metabolic proteins that are designed based on target specificity can yield insecticides with no significant toxicity to non-target species. These metabolic modulators combined with each other or with synergists, sterilants, and transmission-blocking agents in a single product, can yield potent malaria intervention strategies. These combinations can provide multiple means of controlling the vector. Also, they can help to slow down the development of insecticide resistance. Moreover, some metabolic proteins can be modulated for mosquito population replacement or suppression strategies, which will significantly help to curb malaria transmission.
\end{abstract}

Keywords: Immune response, Insecticide, Insecticide resistance, Plasmodium, Vector control, Acetylcholinesterase

\section{Background}

Malaria remains a universal health challenge affecting over 200 million of the world's population annually. Although malaria burden is highest in Africa (93\% of malaria cases), a global incidence rate of 57 cases per 1000 population has been reported annually between 2014-2018 [1]. Malaria is an infectious disease caused by the parasite Plasmodium and transmitted by female Anopheles mosquitoes, which vary from one region to

\footnotetext{
*Correspondence: rainer.koenig@uni-jena.de; ezekiel. adebiyi@covenantuniversity.edu.ng

${ }^{1}$ Covenant University Bioinformatics Research (CUBRe), Covenant University, Ota, Ogun State, Nigeria

${ }^{4}$ Integrated Research and Treatment Center, Center for Sepsis Control and Care (CSCC), Jena University Hospital, Am Klinikum 1, 07747 Jena, Germany

Full list of author information is available at the end of the article
}

another [2, 3]. The major Anopheles species include $A n$. gambiae, An. stephensi, An. dirus, An. coluzzii, An. albimanus, An. funestus and An. arabiensis amongst others. Transmission of Plasmodium depends on the completion of its developmental cycle in the mosquito, a process that occurs alongside the digestion of the blood meal and egg development in the mosquito [4]. This blood meal is crucial for oogenesis [5]. Hence, Anopheles mosquito's ability to transmit malaria is directly linked to its ability to feed on and digest a blood meal from a malaria-infected person [6]. These processes i.e. blood digestion, egg development and parasite development in the mosquito occur simultaneously and are tightly linked to metabolism. Metabolism refers to all the enzyme-catalyzed chemical transformations that occur in the cell of an organism [7] and metabolic proteins consist of enzymes as well as 
transporters. Since metabolism is substantial for the survival and proper functioning of an organism, metabolic proteins provide a good biological space to serve as vector control targets.

Interestingly, some metabolic proteins involved in digesting ingested blood, absorbing nutrients and oogenesis, also play a role in the development of Plasmodium in the mosquito [8]. For example, trypsin produced in Anopheles midgut might activate Plasmodium chitinase that allows the parasite to evade physical barriers in the mosquito [9]. In addition, ingestion of the parasite by Anopheles triggers an innate immune response in the mosquito to circumvent parasite development [10]. This immune response is a cascade of reactions involving some metabolic proteins of the mosquito. This interplay suggests the importance of metabolic proteins in Plasmodium development in the mosquito and consequently malaria transmission. Aside from being involved in blood digestion and parasite development, Anopheles metabolic proteins such as the acetylcholinesterase (AChE) are, also important targets for vector control strategies [11]. Figure 1 gives a schematic overview of the contributions of the metabolic proteins of Anopheles mosquitoes in malaria transmission and control.

In the past decades, vector control greatly depended on the use of insecticides for indoor residual spraying (IRS) and insecticide-treated nets (ITNs) [12]. These strategies greatly reduced malaria deaths between 2010 and 2015, as $50 \%$ reduction in malaria deaths was reported and $79 \%$ of this reduction was attributed to insecticide use [13]. Some insecticides target metabolic proteins. For instance, $\mathrm{AChE}$ has been the only target of organophosphate and carbamate insecticides for many years [14]. In addition, $\mathrm{AChE}$ is the target for temephos and fenthion that are organophosphate insecticides and target the larval stage of mosquitoes, and thus, are used in larviciding strategies [15]. These larvicides, upon application to breeding sites of mosquitoes, prevent their further development into adult forms, consequently, reducing adult mosquito population density and ultimately decreasing malaria transmission rates [16]. Meanwhile, the toxicity of many of the currently available insecticides to non-target species and the ever increasing resistance of Anopheles to commonly used classes of insecticides, necessitate the identification of novel targets for vector control [17-21]. Also, metabolic resistance to insecticides is mediated by the activities of detoxifying enzymes [22] and there is evidence that combining insecticides with the inhibitors of these enzymes can considerably reduce insecticide resistance [23]. Therefore, the modulation of metabolic proteins provides a plethora of potential intervention strategies.

Since Anopheles metabolic proteins perform many crucial functions that contribute to malaria transmission and control, a critical review of their roles can provide insights into the possibilities of utilizing Anopheles metabolic proteins for more targeted vector control strategies. Therefore, this review summarizes the information on the role of Anopheles metabolic proteins in the transmission and control of malaria as well as gives insights into future targeted vector control strategies. The role of metabolic proteins is discussed under the following headings: insecticide target; resistance to insecticides; blood digestion; immune response; and Plasmodium development in the mosquito, and their manipulation for vector control strategies.

\section{Metabolic proteins as insecticide targets}

Insecticides are crucial for controlling the malaria vector and consequently, preventing malaria transmission. The four main classes of insecticides used for both indoor and outdoor spraying are organophosphates, organochlorides, carbamates and pyrethroids. Pyrethroids are used in ITNs because of their insecticidal potency and relative safety for domestic use [24]. Many of the known insecticides act on proteins that mediate neuronal processes. Examples of these insecticide targets are AChE, gammaaminobutyric acid (GABA)-chloride ionophore complexes, sodium ion channels [25-27]. However, out of the four classes of insecticides employed for malaria control program, only carbamates and organophosphates target a metabolic protein.

Organophosphate and carbamate insecticides competitively inhibit AChE (EC 3.1.1.7), an enzyme that hydrolyzes acetylcholine into acetate and choline [25, 28]. This hydrolysis reaction terminates the transmission of the cholinergic neuronal signal after an excitation signal [29]. Inhibition of this reaction results in continuous stimulation of the nervous system and consequently leads to the death of the mosquito [30]. These insecticides elicit their inhibitory effects by forming a covalent bond with the catalytic serine residue of AChE [25]. Most insects, including Anopheles, have two AChE genes, ace1 (AChE1) and ace2 (AChE2) [31, 32]. However, AChE1 is the major nervous system cholinesterase in many of these insects and experimental evidence exists showing that AChE1 hydrolyzes most acetylcholine in An. gambiae [33]. Thus, AChE1 is the target for carbamates and organophosphates in Anopheles species.

A study comparing the effect of inhibiting the two AChE genes in Tribolium castaneum (TcAChE1 and TcAChE2) revealed that while the inhibition of TcAChE1 resulted in mortality, inhibition of TcAChE2 by RNAi led to a reduction in egg-laying and hatching, and retarded insect development [34]. Similarly in An. gambiae, $\mathrm{AChE} 1$ is the major $\mathrm{AChE}$ insecticide target while 
AChE2 was suggested to perform some other biological roles other than cholinergic functions [33]. Therefore, An. gambiae AChE2 may play a role in reproduction and development of the mosquito. Further research is necessary to confirm these as AChE2 may be a potential target for manipulation or inhibition to achieve population suppression of mosquitoes.

In general, carbamate and organophosphate insecticides are very important classes of insecticides as they have been considered as alternatives for use in ITNs [11]. However, like most insecticide classes, resistance to carbamates are increasingly reported in Anopheles. Hence, organophosphates remain the main class of insecticide used for IRS or resistance management by the National Malaria Control Programmes in most African countries $[35,36]$. In some recent studies, $100 \%$ susceptibility to organophosphate insecticides in An. gambiae and An. funestus was observed [37, 38], emphasizing the importance of AChE as a crucial target for malaria vector control strategies.

Aside from insecticide resistance evolving in Anopheles, another major concern with currently available insecticides is their toxicity to non-target species [39]. This is because most insecticides inhibit proteins that are generally conserved across species in a non-specific manner. For example, organophosphates such as paraoxon are irreversible inhibitors of AChE, mediating their action by phosphorylating the highly conserved catalytic serine residue in AChE [40]. The conservation of AChE catalytic serine residue was examined in 13 animal species using Clustal Omega version 1.2.4 [41] on the European Molecular Biology Laboratory-European Bioinformatics Institute's (EMBL-EBI) platform for multiple sequence alignment (MSA) [42] (Additional file 1: Figure S1). It was observed that this catalytic serine residue is conserved across all the species of animals that included insects, mammals, birds, nematode and fish (Fig. 2). In particular, the inhibition of AChE by paraoxon, an organophosphate insecticide, results in covalent attachment of a diethyl phosphonate (DEP) to the side-chain of the catalytic serine. To compare the interaction of DEP with human AChE (hAChE) and An. gambiae AChE (AgAChE), DEP-bound hAChE (PDB ID: 5hf5) [43] was aligned to AgAChE (PDB ID: 5x61) [44] using PyMOL [45] (Fig. 3). Both hAChE and AgAChE interacted with DEP by binding conserved residues; DEP binds catalytic serine 203 in hAChE and catalytic serine 360 in AgAChE through covalent interaction. Additionally, DEP interacts with Gly122, His447 and Ala204 in hAChE as well as their conserved counterparts, i.e. Gly280, His600 and Ala361 in AgAChE through hydrogen bonds. Although organophosphate insecticides are irreversible inhibitors of AChE, carbamates are its reversible inhibitors that carbamylate its catalytic serine residue [14]. Therefore, these insecticides inhibit AChEs in non-target species and cause severe toxicity problems.

Since most of these insecticides target the nervous system, and children are more susceptible to insecticide toxicity, neurotoxicity in children due to insecticides exposure is of increasing concern $[18,46]$. To address this problem of toxicity, more specific insecticides have to be developed for known insecticide targets or newly identified ones. Some studies have identified inhibitors that have greater selectivity for AgAChE than hAChE. An example of this was reported in a study in which differential high throughput screening (HTS) of several compounds for selective inhibition of AgAChE was carried out [47]. One of the selective inhibitors identified in their study was a phenoxyacetamide-based inhibitor that was 100-times more selective for AgAChE than for hAChE. In another study, Carlier et al. [48] screened some alkyl

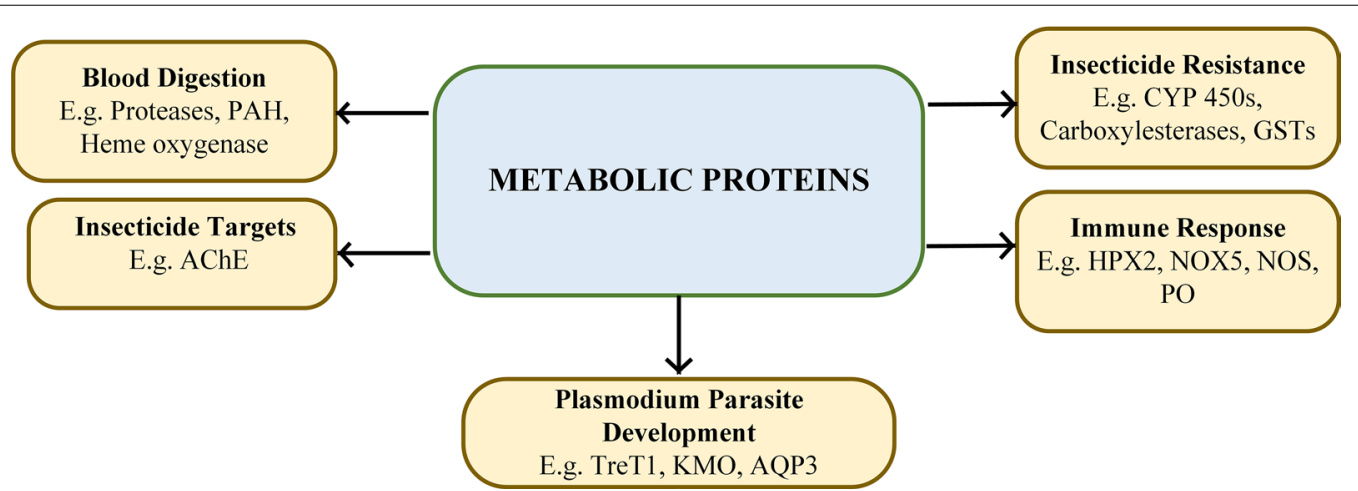

Fig. 1 Role of Anopheles metabolic proteins in malaria transmission and control. Abbreviations: PAH, phenylalanine-4-hydroxylase; AChE, acetylcholinesterase; CYP 450s, cytochrome P450s; AQP3, aquaporin 3; GSTs, glutathione S-transferases; HPX2, heme peroxidase 2; NOX5, NADPH oxidase 5; NOS, nitric oxide synthase; PO, phenoloxidase; TreT1, trehalose transporter; KMO, kynurenine 3-monooxygenase; CEs, carboxylesterases 
chemically substituted 1-alkylpyrazol-4-yl methylcarbamate compounds for their selective inhibition of AChE. They identified three compounds, namely, cyclopentylmethyl pyrazol-4-yl methyl carbamate, cyclobutylmethyl pyrazol-4-yl methyl carbamate and 3-methylbutyl- pyrazol-4-yl methyl carbamate that were 250, 120 and 96 times, respectively, more selective for AgAChE than for hAChE [48]. These two studies suggest that Anopheles AChE can be selectively inhibited by more specific insecticides. Further studies towards identifying these selective inhibitors that could serve as novel insecticides are possible since the crystal structure of the catalytic domain of AgAChE is available [44]. Still, a new insecticide target should ideally be a protein that is important for the survival of target species and unique to them (i.e. absent in non-target species). Different studies have suggested some metabolic proteins that can serve as possible insecticide targets, namely, carbonic anhydrases, arylalkylamine $\mathrm{N}$-acetyltransferases, V-ATPase and phosphofructokinase (PFK) [49-52]. These potential insecticide targets are further discussed in the subsection "Identifying novel insecticide targets".

In addition to being targets for adulticides, metabolic proteins are targets for larvicides. For example, temephos is an organophosphate larvicide targeting AChE. Another group of larvicides, benzoylurea (BFU), inhibits chitin biosynthesis by targeting chitin synthase 1 (CHS1: EC 2.4.1.16) [53]. Chitin biosynthesis is essential for insect growth; therefore, its inhibitors are insect growth regulators, affecting the growth and survival of insects. One of the most effective larvicides currently available is diflubenzuron (DFB), a BFU, which is used in the control of Culex pipiens [54]. Novaluron, another CHS1 inhibitor is effective against Aedes aegypti, inhibiting adult emergence by at least 70\% [55]. In a study by Zhang et al. [56], exposure of third-instar larvae of An. gambiae to $50 \mu \mathrm{g} / \mathrm{l}$ DFB resulted in about $60 \%$ mortality in $48 \mathrm{~h}$. Although in their study, DFB had minimal in vitro inhibition on $A n$. gambiae CHS1 and no in vivo inhibition on An. gambiae pupae, a different study showed that knockdown of CHS1 by RNAi in An. gambiae increased toxicity to DFB in the mosquito [57]. These studies suggest that CHS1 can be targeted for vector control strategies. Further studies investigating the inhibitory effect of BFUs on CHS1 in Anopheles and the exposure effect of other larval stages to BFUs can guide the use of the larvicides in malaria control.

\section{Metabolic proteins and insecticide resistance}

The intense use of the few available insecticide classes for IRS and ITNs has resulted in increased resistance in mosquitoes [21]. Insecticide resistance in Anopheles has been reported for all the four main classes of insecticides being used in malaria control [1]. In 2017, Riveron et al. [58] observed high resistance to permethrin (a pyrethroid insecticide) and dichlorodiphenyltrichloroethane (DDT) in An. gambiae with no significant mortalities after exposing the mosquitoes to these insecticides for $6 \mathrm{~h}$. Their study corroborated earlier reports on the development of DDT and pyrethroid resistance in Anopheles [59-62]. The two most characterized insecticide resistance mechanisms are metabolic resistance and targetsite resistance [63]. In addition to these, there are three other insecticide resistance mechanisms, namely, behavioral resistance, cuticular resistance, and sequestration by the chemosensory proteins sensory appendage protein 2 (SAP2) [64, 65]. Understanding these mechanisms is important in guiding decisions on resistance management strategies [66].

\section{Metabolic resistance}

Metabolic resistance to insecticides is caused by changes in the sequestration, transport and detoxification of insecticides and their metabolites [66]. Insecticides are xenobiotics (i.e. foreign to the body); thus, Anopheles xenobiotics detoxifying enzymes break down insecticides into less harmful substances, hence overcoming the deleterious effect of the insecticides and resulting in the evolvement of insecticide resistance [67]. Xenobiotic enzymatic detoxification occurs in two phases: phase 1 and phase 2. Phase 1 involves oxidation and reduction

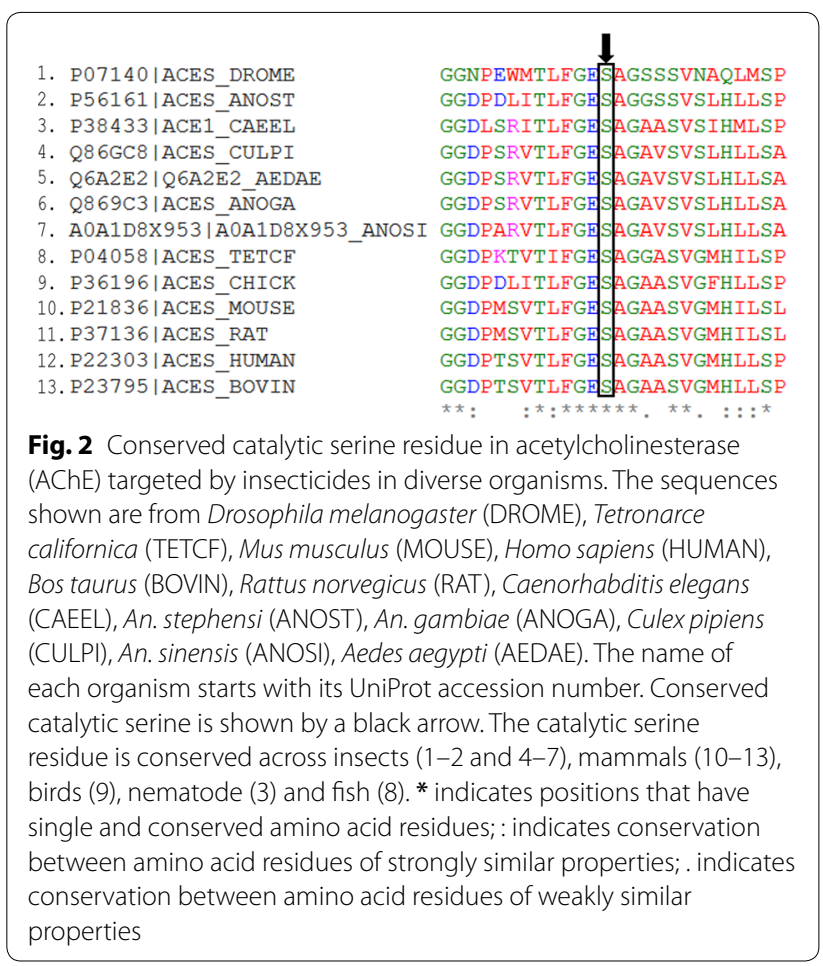




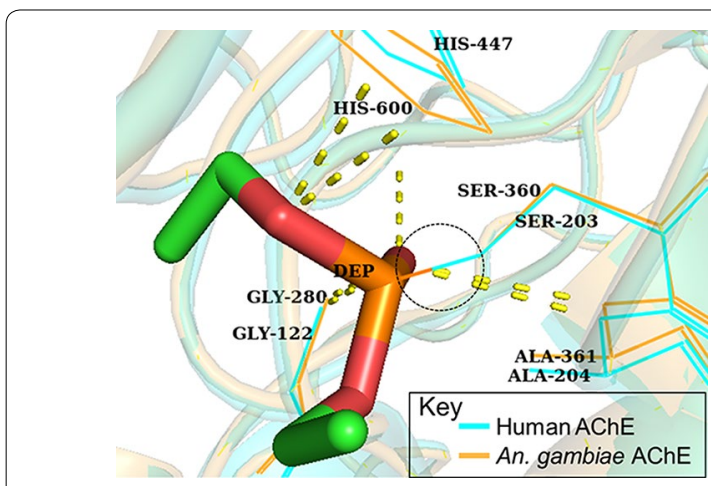

Fig. 3 Paraoxon binds conserved residues in both humans' and mosquitoes' acetylcholinesterase (AChE), hence toxic to humans. Diethyl phosphonate (DEP) from paraoxon binds covalently to Ser203 in humans AChE (hAChE; PDB ID: 5hf5) and Ser360 in An. gambiae AChE (AgAChE; PDB ID: 5x61), thus inhibiting them. Covalent binding is highlighted in black dotted circle. Also, DEP interacts with Gly122, His447 and Ala204 in hAChE, Gly280, His600 and Ala361 in AgAChE through hydrogen bonds

reactions, adding functional groups to xenobiotics while in phase 2, xenobiotics or end products of phase 1 reactions are conjugated to endogenous molecules such as glutathione [68]. Phases 1 and 2 metabolism of xenobiotics make the xenobiotics more water-soluble and easily excretable from the body [69]. Over-expression of some xenobiotics detoxifying enzymes is associated with Anopheles' resistance to insecticides [70]. This over-expression can be as a result of gene amplification, changes in regulatory elements or promoter regions of genes [64]. Three main classes of xenobiotic detoxifying enzymes that contribute to insecticide resistance in Anopheles are cytochrome P450 monooxygenases (CYP), glutathione S-transferase (GSTs) [71] and carboxylesterases (CEs) [72].

Cytochrome $\mathrm{P} 450$ monooxygenases enzymes are detoxifying enzymes that participate in phase 1 of the xenobiotic metabolism. They catalyze the oxidation or reduction of compounds (endogenous and exogenous compounds) mainly into less harmful compounds by converting non-polar xenobiotics into more polar and excretable forms [73]. The end products of the reactions catalyzed by CYPs are subsequently conjugated with endogenous molecules by phase 2 enzymes, thereby making them more water-soluble and better excretable [68]. Cytochrome P450 enzymes such as CYP6M2, CYP6P1, CYP9K1, CYP6P3, CYP4H17, CYP6Z1 and CYP6Z2 have been associated with insecticide resistance in An. gambiae [71, 74-77], while CYP6P9a and CYP6P9b contribute to resistance in An. funestus [78]. In a study by Weedall et al. [79], An. funestus mosquitoes having a homozygous resistance allele, CYP6P9a_R were observed to have a high resistance to pyrethroid insecticides and ITNs. Their study revealed two findings: first, that a polymorphism in the cis-regulatory element drives this allele and second, that upon exposure to ITNs, mosquitoes with this allele had a greater survival and subsequently were more successful in blood-feeding than mosquitoes without this allele. Table 1 gives an overview of CYP450 and other metabolic enzymes that contribute to the development of insecticide resistance in different Anopheles species. Aside from contributing to insecticide resistance, CYP 450s are also involved in the bioactivation of organophosphate insecticides [80]. Many organophosphate insecticides are not active anticholinesterase, they require bioactivation by CYP 450 s converting them from their phosphorothionate form to a toxic oxon form which inhibits AChE [81]. A good example of this is parathion, which is converted into paraoxon (the active acetylcholinesterase inhibitor) by CYPs [82].

Glutathione S-transferases (GSTs) are phase 2 detoxifying enzymes [68]. They catalyze the conjugation of endogenous compounds or xenobiotics with glutathione, thus detoxifying the xenobiotics, increasing their solubility and leading to their excretion from the mosquito [67]. GSTs are known to detoxify organophosphate insecticides, metabolize DDT to dichlorodiphenyldichloroethylene (DDE), a non-toxic metabolite [83, 84], and contribute to pyrethroid resistance [85]. Functionally, GSTs sequester the pyrethroid insecticides or detoxify their lipid peroxidation products, thereby reducing the capacity of pyrethroids to cause oxidative stress and death of the mosquitoes [86]. Over-expression of GSTs has been implicated in resistance to all the main classes of insecticides used in malaria vector control. There are about 13 classes of GSTs, with four classes, i.e. Omega, Theta, Zeta and Sigma, occurring in almost all metazoans [87] while Delta (GSTD) and Epsilon (GSTE) occur exclusively in insects and are key players in insecticide resistance [88, 89]. For example, GSTE2, GSTE5, GSTM1, GSTMS3 and GSTS1-2 have been implicated in pyrethroid resistance in An. coluzzii [90], while GSTD3, GSTE2 and GSTS1-2 are associated with insecticide resistance in An. gambiae [71, 75, 91].

Apart from the increased expression of certain GSTs, mutations in GSTs contribute to insecticide resistance. An example is a naturally occurring single amino acid mutation L119F (leucine to phenylalanine) in GSTE2, which confers resistance to DDT in An. funestus [92, 93]. This mutation modified GSTE2-DDT binding cavity, increasing accessibility of DDT by GSTE2 and consequently increased detoxification of DDT to DDE, thereby resulting in resistance to DDT [93]. In a study by Pontes et al. [94], I114T/F120L mutation in GSTE2 of An. gambiae was observed to cause structural rearrangement 
with a displacement of a Glu116 residue. The displaced Glu116 was postulated to act as a base that activated GSH, which bound DDT, leading to DDT resistance in the mosquito [94]. Increased expression of GSTE4 is associated with pyrethroid resistance in An. gambiae and $A n$. arabiensis. However, rather than metabolize pyrethroids, this enzyme binds and sequesters them, thus leading to pyrethroid resistance [95]. Interestingly, vector competence, which is the capability of a vector to acquire, maintain and successfully transmit a pathogen, may be affected by the L119F GSTE2 allele [96, 97]. Ndo et al. [97] observed that the frequency of this resistant allele was significantly higher in non-infected An. funestus mosquitoes (55.88\%) compared to their P. falciparum infected counterparts (40.99\%). However, An. funestus mosquitoes with the resistant allele had higher parasite load compared to the susceptible mosquitoes. While the obtained results were contradictory, their study suggested that L119F GSTE2 may impact vector competence by increasing parasite load. A review on the effect of insecticide resistance on Plasmodium development has recently been published [98]. Further studies are required to fully establish the impact of metabolic resistance on vector competence in mosquitoes.

Carboxylesterases (CEs) are another class of detoxifying enzymes that act on insecticides with ester structures by hydrolyzing or sequestering them. In Anopheles species, overexpression of some CEs has been associated with insecticide resistance. For example, $\alpha$-esterase 10 and AChE1 are the main CEs that are associated with pyrethroid resistance in $A n$. sinensis [72], whereas $\alpha$-esterase (gb-COEAE1G) is associated with DDT resistance in An. funestus [93]. Also, $\alpha$ - and $\beta$-esterases are upregulated in malathion-resistant $A n$. stephensi [99]; COEAE3G and COEAE4G are associated with pyrethroid resistance in An. coluzzii [90] whereas COEAE5G is constitutively expressed in permethrin resistant An. coluzzii [100]. Also, genomewide association studies (GWAS) in An. gambiae indicated the role of COEAE1D in insecticide resistance [101].

Transporters are involved in metabolic resistance to insecticides by transporting them away from the target. For instance, ATP-binding cassette (ABC) transporters are involved in insecticide resistance by mediating their transport out of the cell [102]. Inhibition of ABC transporters in An. stephensi larvae was noted to increase their susceptibility to permethrin insecticide [103]. In addition, AnstABCB2, AnstABCBmember6, AnstABCG4 were upregulated in male and female adult $A n$. stephensi in response to permethrin insecticide [104]. Both studies indicate that the increased expression of these transporters upon permethrin exposure is crucial for insecticide transport out of the cell and consequently insecticide resistance.

\section{Target site mechanism}

Target site resistance refers to target site insensitivity to insecticides, reduced ability of insecticides to bind to their protein targets due to the buildup of mutations in the target proteins [105]. These mutations are usually non-silent point mutations in genes that code for the target protein [64]. Of the four classes of insecticides commonly used, only carbamates and organophosphates target a metabolic protein - AChE. A common point mutation associated with insecticide resistance in AChE is a glycine to serine mutation, G119S in An. gambiae, An. coluzzii, An. albimanus $[106,107]$ and An. arabiensis [108]. Owing to the new coding numbering in An. gambiae, codon 119 (G119S) of AChE is now referred to as codon 280 (G280S) [109]. In addition to this mutation, $\mathrm{N} 485 \mathrm{I}$, which is an asparagine to isoleucine mutation in the acetylcholinesterase gene, has been associated with carbamate (bendiocarb) resistance [110]. Apart from the point mutation in acetylcholinesterase which results in an insecticide resistant copy of the ace-1 gene denoted as ace- $1^{R}$, gene duplication of the acetylcholinesterase gene is also linked to insecticide resistance [111]. This duplication creates a permanent heterozygote allele, ace- $1^{D}$, i.e. a susceptible $\left(a c e-1^{S}\right)$ and a resistant copy $\left(\right.$ ace- $\left.1^{R}\right)$ on the same chromosome [106, 112]. Also, homogeneous duplication of the ace- $1^{R}$ gene has been reported and mosquitoes with homogenous duplication are significantly more often resistant [111].

\section{Cuticular resistance}

Cuticular resistance to insecticides in mosquitoes occurs when cuticular proteins are remodeled to prevent or reduce uptake of insecticides [63]. This remodeling involves increasing the thickness of the cuticle, which has been associated with insecticide resistance in Anopheles [113]. CYP4G16 is a metabolic enzyme involved in epicuticular hydrocarbon synthesis through the oxidative decarbonylation of aldehydes to hydrocarbons [114, 115]. CYP4G16 has a markedly increased expression in insecticide-resistant strains of An. gambiae [116], An. arabiensis [117] and An. coluzzii [90]. It is involved in the remodeling of the cuticle, thereby contributing to insecticide resistance. Balabanidou et al. [114] reported that CYP4G16 contributed to insecticide resistance by remodeling the cuticle, hence it was involved in cuticular resistance mechanism rather than in metabolic resistance like other CYPs.

Apart from the metabolic proteins with known resistant mechanisms reviewed above, some other metabolic 
Table 1 Classes of insecticides, their resistance mechanisms and associated proteins in Anopheles species

\begin{tabular}{|c|c|c|}
\hline \multirow[t]{2}{*}{ Insecticide class } & \multicolumn{2}{|l|}{ Resistance mechanism and associated proteins } \\
\hline & Target site & Metabolic resistance \\
\hline \multirow[t]{2}{*}{ Organophosphates } & \multirow{2}{*}{$\begin{array}{l}\text { AChE-G119S in An. gambiae, An. arabiensis, An. coluzzii, An. } \\
\text { albimanus }[106-108,253,254]\end{array}$} & GSTE2 in An. gambiae [20] \\
\hline & & a- and $\beta$-esterases in An. stephensi [99] \\
\hline \multirow[t]{2}{*}{ Organochlorines, e.g. DDT } & \multirow[t]{2}{*}{ Target site is not a metabolic protein } & CYP6M2, CYP6P3, GSTD3, GSTE2, in An. gambiae [255] \\
\hline & & $\begin{array}{l}\text { CYP6P9a, CYP6P9b, GSTD1-5, GSTD3, GSTE2, a-esterase in An. } \\
\text { funestus }[78,256]\end{array}$ \\
\hline \multirow[t]{8}{*}{ Pyrethroids } & \multirow[t]{8}{*}{ Target site is not a metabolic protein } & $\begin{array}{l}\text { CYP4G16 (cuticular resistance), CYP6M2, CYP6P3, CYP6Z2, } \\
\text { COEAE1D, GSTE2, GSTD1, GSTD3, GSTE4 in An. gambiae [20, } \\
66,91,95,101,257,258]\end{array}$ \\
\hline & & $\begin{array}{l}\text { CYP6M7, CYP6P9a, CYP6P9b, CYP6P4, CYP9J11, CYP9K1 in An. } \\
\text { funestus }[78,79,256,259,260]\end{array}$ \\
\hline & & CYP6AA3 and CYP6P7 in An. minimus [261] \\
\hline & & $\begin{array}{l}\text { CYP325C1, GSTS1-1, GSTS1-2, GSTMIC2, COEJHE2, AnstABCB2, } \\
\text { AnstABCBmember6, AnstABCG4 in An. stephensi }[104,262]\end{array}$ \\
\hline & & $\begin{array}{l}\text { CYP6P1, CYP6Z1, CYP6Z3, CYP9K1, CYP9J5, CYP9M1, GSTE2, } \\
\text { GSTE5, GSTM1, GSTMS3, GSTS1-2, GSTS1-1, GSTE4, COE- } \\
\text { AE3G, COEAE4G, COEAE5G in An. coluzzii }[77,90,100]\end{array}$ \\
\hline & & $\begin{array}{l}\text { CYP6AG2, CYPZ1, TPX2, CYPZ2, CYP6P1, CYP6P4, GSTE4 in An. } \\
\text { arabiensis }[95,263,264]\end{array}$ \\
\hline & & $\begin{array}{l}\text { CYP4H14, CYP6AA1, CYP6M3, CYP6M17, CYP6P2, a-esterase } \\
\text { 10, AChE1 in An. sinensis [72, 265] }\end{array}$ \\
\hline & & CYP4C26, CYP6P5, CYP9K1 in An. albimanus [266] \\
\hline \multirow[t]{2}{*}{ Carbamates } & \multirow[t]{2}{*}{$\begin{array}{l}\text { AChE-G119S in An. gambiae, An. arabiensis, An. coluzzii, An. } \\
\text { albimanus. N485I in An. funestus [106-108, 110, 254] }\end{array}$} & $\begin{array}{l}\text { CYP4H17, CYP6P3, CYP6Z3, CYP6Z1, CYP12F2, CYP6M3 } \\
\text { CYP6P4, GSTD3 in An. gambiae }[20,75,267]\end{array}$ \\
\hline & & CYP6M2, CYP6P3, CYP6Z1 in An. funestus [268] \\
\hline
\end{tabular}

proteins are over-expressed in insecticide resistant mosquitoes compared to susceptible mosquitoes. However, their contributions to insecticide resistance and mechanisms of actions have not been validated. In a study by Isaacs et al. [75], glycine N-methyltransferase, glyceraldehyde-3-phosphate dehydrogenase and apyrase were found to be upregulated in bendiocarb resistant $A n$. gambiae. Riveron et al. [93] observed that thioredoxin peroxidase (TPX2), sterol desaturase, bifunctional purine biosynthesis protein, sorbitol dehydrogenase, UDPglucuronosyltransferase (UGT), calcium-transporting ATPase, catalase, and short-chain dehydrogenases were up-regulated in DDT resistant An. funestus mosquitoes. A different study on pyrethroid resistance in $A n$. coluzzii revealed that chymotrypsin-1, aquaporin and ATP synthase levels were elevated in the resistant mosquitoes compared to the susceptible mosquitoes [90]. In a recent study on $A n$. sinensis, upregulated expression of UGT308D3 and UGT302A3 were associated with pyrethroid resistance [118]. In Cx. pipiens, carbonic anhydrase, trehalase and chitin synthase were reported to contribute to pyrethroid resistance $[119,120]$. In Anopheles, there is need to validate the possible contributions of these proteins to insecticide resistance and their mode of actions.

\section{Metabolic proteins, blood digestion, immune response and Plasmodium parasite development in Anopheles}

The basal metabolic activities of Anopheles mosquitoes are sustained by feeding on sugar meals. However, female Anopheles mosquitoes require a blood meal to obtain the needed proteins for egg development [121]. When blood is ingested from malaria infected individuals, Plasmodium parasites are ingested as well by Anopheles. The ingested blood must be digested to release nutrients required for oogenesis. This process necessitates the activation and involvement of several metabolic proteins [122]. Heme in blood also triggers the heme detoxification pathway and the presence of parasites triggers the immune response in the mosquito [123]. In all these processes, metabolic proteins play crucial roles in contributing to blood digestion, parasite development or removal, and consequently malaria transmission or prevention.

\section{Metabolic proteins and blood digestion in Anopheles}

Blood digestion in Anopheles is a well-coordinated process and studies involving transcriptomic and proteomics analyses comparing sugar-fed and blood-fed mosquitoes revealed that metabolic proteins are critical in blood digestion [124, 125]. The ingested blood is transported 
to the midgut and induces the synthesis of the peritrophic membrane [124]. Formation of the peritrophic membrane is important because iron from heme of the blood and human antibodies can harm the mosquitoes [125]. Thus, this membrane protects the mosquitoes. The peritrophic membrane surrounds the blood meal, regulates the digestion rate by controlling the translocation of digestive enzymes and digestion products across the membrane [126]. It also regulates heme detoxification and provides a physical barrier, which is the first level of defense against Plasmodium parasites [123, 127]. In the midgut, proteases and other digestive enzymes break down the ingested blood, and the resulting nutrients are processed in the fat body and taken up by the ovaries for egg development [128].

Blood meals have a large content of proteins [122, 129]. Thus, proteolytic proteins involved in protein digestion are highly expressed in blood-fed mosquitoes and catalyze the cleavage of proteins into amino acids. This is important because seven amino acids (leucine, valine, isoleucine, phenylalanine, lysine, arginine and histidine) are essential for egg development in mosquitoes. Hence, they must be obtained from blood meals [130]. Several transcriptome studies in An. stephensi and An. gambiae revealed that proteases such as trypsin 1 and 2, chymotrypsin, carboxypeptidase, aminopeptidase and a serine protease were highly expressed in blood-fed females when compared with their sugar-fed counterparts [128, 131-133]. Interestingly, these proteases have been reported to contribute to Plasmodium clearance in the mosquito. For example, a proteomic study that compared species of An. culicifacies mosquitoes that are susceptible to Plasmodium infection with their refractory counterparts, revealed that chymotrypsin 2 was upregulated in the refractory species and that chymotrypsin 2 may be involved in preventing Plasmodium development in the mosquitoes [134]. This may be explained by the destruction of ookinetes by the proteolytic enzyme since early forms of Plasmodium parasite in the mosquito, within $24 \mathrm{~h}$ post-blood-feeding (pbf), are vulnerable to the action of digestive enzymes $[135,136]$. These parasite forms include gametocytes, zygotes and undifferentiated ookinetes. Baton \& Ranford-Cartwright [136] compared the time points at which peak expression levels of trypsin and chymotrypsin occurred in An. albimanus and An. stephensi. They observed a peak expression at $14 \mathrm{~h}$ and $20 \mathrm{~h}$ in An. albimanus as opposed to $30 \mathrm{~h}$ and $36 \mathrm{~h}$ in An. stephensi for the two enzymes trypsin and chymotrypsin, respectively. This difference may contribute to the disparity in Plasmodium susceptibility in the two mosquito species. While An. albimanus was refractory to P. falciparum (3D7A), An. stephensi was susceptible to it [136]. Their study revealed that early expression of digestive enzymes following a blood meal may be important for parasite clearance, and that the time at which peak expression of proteases (and other digestive enzymes in extension) is achieved, differed across Anopheles species. In addition, this difference in peak expression time may explain the downregulated levels of trypsin that was observed at $24 \mathrm{~h}$ pbf in other studies, e.g. in An. dirus [125]. Therefore, in studying expression patterns of proteases and metabolic proteins in general, and their impact on Plasmodium development in Anopheles species, a time series experiment may be more revealing.

Proteases act on parasite forms that are close to the peritrophic membrane. However, parasites that are farther away in the center of the blood meal are able to gain time and differentiate into mature forms, capable of responding to and escaping from the action of the digestive enzymes [137]. In a study by Baia-da-Silva et al. [135], the development of peritrophic membrane in $A n$. aquasalis was hindered and the effect of this absence on Plasmodium vivax development was verified. They observed that the absence of this membrane enhanced interaction of digestive enzymes with parasites and resulted in increased parasite killing. They reported that trypsin contributed to parasite clearance in mosquitoes lacking peritrophic membrane and the subsequent treatment with a trypsin inhibitor increased infection intensity [135]. However, an earlier study by Shahabuddin et al. [138], showed that Plasmodium responded to elevated trypsin-like protease levels by increased secretion of chitinase, with which it digested the peritrophic membrane and avoided the action of digestive proteases. Huber et al. [139] reported that parasite chitinase was not secreted until about $15-20 \mathrm{~h}$ pbf of mosquitoes when the parasites were developing from zygotes to ookinetes. Also, they suggested that the effect of proteases on parasite development depended on the timing of protease expression and the level of interactions or contact of digestive proteases with parasites [139]. A study that compared An. dirus strains susceptible to $P$. yoelii nigeriensis with refractory strains showed that trypsin and aminopeptidase expression were not different between the two strains [140]. A similar study that compared An. stephensi strains susceptible to $P$. falciparum with refractory strains revealed that trypsin activity was not different between the two strains, though, aminopeptidase activity was higher in refractory mosquitoes [141]. While these two studies suggest that trypsin does not affect Plasmodium development, other studies showed that trypsin affects Plasmodium development in other Anopheles species. These studies suggest that increased early expression of trypsin and chymotrypsin pbf contributes to parasite clearance in 
mosquitoes. Thus, strategies that can reprogram mosquitoes to prevent peritrophic membrane development or to express proteases early enough upon blood-feeding (i.e. before parasites differentiate into forms that can respond to protease activity by secreting chitinase), may decrease parasite development in the mosquitoes thereby preventing malaria transmission. However, the possibility and sustainability of this reprogramming remains a question to be answered.

Shi et al. [142] assessed the expression levels of carboxypeptidase A and B in An. sinensis (AsCPA and AsCPB) $24 \mathrm{~h}$ pbf and noted that five out of the eight carboxypeptidases that were present in the mosquito were upregulated upon blood-feeding, i.e. AsCPA-I, AsCPAIII, AsCPA-IV, AsCPA-VI and AsCPB-II. This may point to their probable role in blood digestion. Similarly, carboxypeptidase (CPA) levels were observed to be significantly elevated in P. berghei infected, blood-fed $A n$. stephensi mosquitoes compared to non-infected, bloodfed controls [143]. In their study, feeding mosquitoes with $P$. berghei parasitized blood meal containing CPA targeting antibodies, hampered the development of the parasite in the mosquito's midgut [143]. Furthermore, their study revealed the importance of carboxypeptidase in Plasmodium parasite development in mosquitoes. Thus, carboxypeptidase can be inhibited or targeted with antibodies to prevent malaria transmission.

Carbohydrates are important energy sources in insects that can be obtained from their diet directly or synthesized from amino acids or lipids. As such, enzymes involved in carbohydrate and lipid metabolism such as lipases, adenosine monophosphate (AMP) dependent ligase, $\alpha$-glucosidases and $\alpha$-amylases are differentially expressed during a blood meal [132, 134, 144]. In addition, the pentose phosphate pathway is associated with blood digestion [145]. Metabolomics analysis of $A n$. gambiae $24 \mathrm{~h}$ pbf by Champion \& Xu [146], revealed an increased concentration of glucose 6 phosphate and 6-phosphogluconate. This may be indicative of increased expression of the enzymes that are involved in their production, namely, glucose-6-phosphate dehydrogenase (G6PDH) and 6-phosphogluconate dehydrogenase (6-PGDH). These reactions were necessary for replenishing NADPH levels, a metabolite that is needed for maintaining the redox metabolism [145]. This replenishment is very important because reactive oxygen species (ROS) generation is increased during blood-feeding, particularly during parasitemia [147]. In female mosquitoes, nutrients from digested blood are transported to the ovary for oogenesis. This requires the action of transporters such as lipid transporters that mobilize lipids from the midgut to the ovaries [148]. Lipids are generally important components of cell membranes and include fatty acids, phospholipids and sterols. Four lipid transporters have been observed to be upregulated pbf in Anopheles [149].

After a blood meal, Anopheles mosquitoes reduce their flight activity and seek a resting place. In blood-fed $A n$. gambiae mosquitoes, pyrroline-5-carboxylate reductase and proline oxidase were reported to be downregulated. Both enzymes are required for the metabolism of proline for energy production during flight [144]. Inhibition of any of these enzymes can prevent flight of mosquitoes, thereby limiting their subsequent access to humans for malaria transmission. Although there is currently no evidence for the use of these kinds of inhibitors in vector control, evidence exists that the inhibitors of enzymes involved in energy production during flight can reduce flight activity. Generally, insects differ in the substrate used to fuel flight, varying from the use of trehalose to the use of diacylglycerol or proline [150]. For example, while blood-sucking insects like Anopheles, Aedes and tse-tse fly use proline, some other insects, such as locust and, cockroaches use trehalose instead [151-154]. In Aedes, a combination of proline and pyruvate (pyruvate can be obtained from trehalose metabolism since trehalose is the major sugar in insect hemolymph) provided the highest energy needed for flight [155]. Similarly, Anopheles can use proline and pyruvate to fuel flight [154]. Exposure of cockroaches to a trehalase inhibitor, validoxylamine $\mathrm{A}$, thus preventing trehalose metabolism, led to a 70\% reduction in flight muscle activity and prevented the cockroaches from flying for $>2.5 \mathrm{~min}$ compared to active (1-5 min) and very active (> $5 \mathrm{~min})$ controls [152]. Similarly, validamycin A, a trehalase inhibitor, prevented flight in adult Ae. aegypti mosquitoes in a dose-dependent manner. Mosquitoes exposed to $0.5 \mathrm{mg} / \mathrm{ml}$ of validamycin A were unable to fly at all [156]. In addition, validamycin A decreased egg hatching, pupation time and prevented emergence of female Ae. aegypti mosquitoes, thus, offering multiple control strategies [156]. Gleaning on these and considering the fact that the ability of insects to fly is crucial to seek a host for transmission, inhibiting pyrroline-5-carboxylate reductase, proline oxidase or trehalase needed to provide fuel for flight may help reduce malaria transmission. Inhibitors can be designed for these targets, which can be incorporated into insecticides.

Ingestion and digestion of a blood meal in mosquitoes lead to the production of reactive species such as hydrogen peroxide $\left(\mathrm{H}_{2} \mathrm{O}_{2}\right)$, so causing oxidative stress in the mosquito [157]. Some antioxidant enzymes such as catalase, help to scavenge these free radicals, thereby reducing oxidative stress and preventing subsequent damage to the mosquitoes. Catalase is an antioxidant enzyme that breaks down $\mathrm{H}_{2} \mathrm{O}_{2}$, thereby preventing the formation of the hydroxyl radical. The levels of $\mathrm{H}_{2} \mathrm{O}_{2}$ in 
the hemolymph are significantly higher in An. gambiae strains that are refractory to Plasmodium compared to the susceptible strains [157]. dsRNA silencing of catalase resulted in reduced ookinete survival in An. gambiae G3 strains [158]. In another study, silencing of catalase in An. gambiae and subsequent blood-feeding of mosquitoes resulted in higher mortality [159]. Therefore, catalase plays a crucial role in regulating immune response to Plasmodium parasite and ensuring the survival of the mosquitoes. Inhibiting catalase offers multiple ways of preventing malaria transmission, by resulting in the death of the mosquito or by supporting parasite clearance in the mosquito.

\section{Metabolic proteins and immune response to Plasmodium infection in Anopheles}

When Plasmodium is picked up during ingestion of parasitized blood in mosquitoes, the innate immune system of the mosquito is triggered and tries to eliminate the intruding parasite [160]. The first level of defense is the physical barrier, i.e. the peritrophic membrane. Plasmodium parasites that successfully emerge from the peritrophic membrane, encounter another level of defense known as the innate immune responses in the mosquito involving processes such as phagocytosis, melanization and lysis $[2,4]$. These processes result in massive parasite losses and only parasites that escape this immune response develop into sporozoites that can be transmitted during a subsequent blood meal [4]. The immune response process in Anopheles is the subject of several reviews [161-164]. The process involves the action of some metabolic proteins that are discussed in this subsection.

Difference in metabolic activities between refractory and susceptible strains of An. gambiae have been reported to influence their susceptibility to $P$. berghei infection [165]. These differences include increased expression of glycolytic enzymes and impaired mitochondrial respiration leading to increased generation of ROS in refractory strain (An. gambiae L3-5 strain) compared to the susceptible strain (An. gambiae G3 strain) [165]. In addition, the increased ROS generation resulted in higher parasite clearance through melanization but with fitness costs because the refractory strains had a lower lifespan than the susceptible strains due to the damaging effects of ROS [165].

ROS mediates Anopheles immunity [158, 166]. The increased generation of these reactive species such as superoxide anion, $\mathrm{H}_{2} \mathrm{O}_{2}$, nitric oxide (NO) in Anopheles, limit the development of Plasmodium in the mosquito $[167,168]$. Heme peroxidase, HPX2 and NADPH oxidase 5 (NOX5) in An. gambiae were involved in P. berghei clearance through nitration of epithelial cells [169]. Also, increased expression of nitric oxide synthase (NOS), the enzyme that synthesizes NO, and enhanced peroxidase activity are important steps in the Anopheles immune response to Plasmodium infection [170]. NOS, NOX5 and HPX2 are important for Anopheles immune response to parasite challenge since they mediate epithelial nitration, marking the parasite for clearance by TEP-mediated lysis [169]. NO activates the synthesis of antimicrobial peptides (AMP) that are responsible for parasite killing [171]. Luckhart et al. [172] reported that inducible NOS were upregulated in $A n$. stephensi upon infection with Plasmodium parasite. Also, they noted that inhibiting NOS reduced parasite clearance while providing L-arginine (a substrate required by the enzyme for the synthesis of nitric oxide), enhanced parasite clearance [172]. Kajla et al. [173] discovered that heme peroxidase 15 (HPX 15) suppressed immune response of An. stephensi to Plasmodium infection by preventing the recognition of the parasite. They found that silencing HPX15 resulted in increased expression of NOS and parasite clearance [173]. These studies suggest that modulation of inducible NOS levels or activity can enhance refractoriness of mosquitoes to parasite thus preventing malaria transmission.

Clip domain serine protease (CLIP) could positively or negatively regulate TEP-mediated killing of Plasmodium parasite as well as take part in the melanization process of the immune response to Plasmodium infection [174]. Nakhleh et al. [174] found CLIPA14 to negatively regulate mosquito's immune response because its knockdown resulted in increased melanization of Plasmodium parasites. Similarly, a different study identified CLIPA2, CLIPA5 and CLIPA7 as negative modulators of immunity [175]. CLIP serine proteases with a positive modulating effect on mosquito immune response, e.g. CLIPA8, proteolytically activate prophenoloxidase (PPO) to phenoloxidase (PO) [2]. PO catalyzes the biosynthesis of reactive quinines from tyrosine and 3,4-dihydroxyphenylalanine [176]. The resultant quinines produce melanin that crosslinks proteins and forms a capsule around the parasite during encapsulation response against Plasmodium and other parasites [175].

\section{Role of metabolic proteins in Plasmodium parasite development}

Although not directly involved in Anopheles immune response to Plasmodium, some metabolic proteins have been reported to either aid or suppress the development of Plasmodium in mosquito and could serve as possible targets for the prevention of malaria transmission. Examples of these proteins are aquaporin 3 (AgAQP3), trehalose transporter (AgTreT1) and kynurenine 3-monooxygenase (AgKMO) [177-179]. 
AgAQP3 transports water, glycerol and urea. It is important for the survival of Anopheles and development of Plasmodium parasite in the mosquito [178]. Knockdown of AgAQP3 using RNAi, reduced median survival of An. gambiae at $39^{\circ} \mathrm{C}$ and resulted in decreased Plasmodium oocytes formation in the midgut of Anopheles, indicating decreased vector competence [178]. The observed effect of AgAQP3 knockdown was attributed to the importance of AgAQP3 in controlling post-prandial diuresis and maintaining the osmotic balance in the mosquito. Accumulation of glycerol by aquaporin in the cell is also required by the mosquito to enhance its tolerance to cold [180]. Therefore, AgAQP3 is important for both parasite transmission and mosquito survival and may serve as an insecticide target or a target for disruption of parasite development. Target-specific inhibitors of this protein can be designed as insecticides or transmissionblocking agents.

AgTreT1, a trehalose transporter that transports trehalose from the fat body to the hemolymph [177] was observed to be a positive modulator of Plasmodium in Anopheles. Trehalose is an important sugar in insects that helps in regulating the temperature of the insects, thus preventing them from the lethal effects of cold. Silencing of the trehalose transporter using RNAi increased Anopheles refractoriness to Plasmodium [177]. Since aquaporin and trehalose contribute to the maintenance of warm temperature in Anopheles, a condition needed for Plasmodium development and survival of Anopheles, these proteins could serve as possible targets for malaria vector control.

Two main nutrient transporters, lipophorin and vitellogenin, produced by the fat body influence Plasmodium development in Anopheles [5]. Lipophorin is a diacylglycerol-carrying lipoprotein, necessary for transporting lipids while vitellogenin is a protein precursor of egg yolk. These two proteins reduce the parasite-killing potential of TEP1, a major protein involved in the lysis of Plasmodium parasites during Anopheles' immune response upon exposure to the parasite [5]. This makes Anopheles more susceptible to Plasmodium, consequently making it capable of transmitting malaria. Inhibiting these proteins may increase TEP1-mediated lysis, thereby making the mosquito more refractory to Plasmodium. However, inhibiting these proteins would negatively impact egg development. In contrast, while lipophorin and vitellogenin were upregulated in response to blood-feeding, another lipid transporter, apolipophorin (ApoLp) was downregulated in blood-fed mosquitoes [130]. Kamareddine et al. [181] reported that apolipophorin was a negative regulator of thioester protein (TEP) induced immune response. They noted that silencing the apolipophorin gene using RNA interference (RNAi), led to increased
TEP expression [181]. Similarly, silencing of ApoLp-III in An. stephensi led to enhanced induction of NOS, which is important for Plasmodium clearance [182]. Therefore, strategies to downregulate ApoLp in mosquitoes upon blood-feeding may be essential for increased expression of NOS and effective TEP lysis of Plasmodium parasite.

Kynurenine 3-monooxygenase (KMO) is a key enzyme in the biosynthetic pathway that produces xanthurenic acid (XA), which is required to activate guanylyl cyclase $[183,184]$. KMO catalyzes the conversion of L-kynurenine to 3-hydroxy-L-kynurenine, which is processed in a subsequent reaction to XA [185]. XA has been identified as a gamete-activating factor of Plasmodium [184]. The activation of guanylyl cyclase by XA is important for the completion of $P$. berghei development in the midgut of mosquitoes [186]. Knockout of the KMO gene in $A n$. stephensi using transcription activator-like effector nucleases (TALEN) resulted in XA-deficient mosquitoes that had reduced oocytes and sporozoites in their midgut and salivary gland, respectively [179]. Also, the study highlighted the important effects of xanthurenic acid on the development of Plasmodium in Anopheles mosquito and suggested that $\mathrm{KMO}$ is a possible target for blocking malaria transmission. 3-hydroxy-L-kynurenine produced by KMO in the XA biosynthetic pathway is further metabolized by 3-hydroxykynurenine transaminase (3HKT). 3HKT metabolizes 3-hydroxy-L-kynurenine to $\mathrm{XA}$, thus preventing the accumulation of potentially toxic 3-hydroxy-L-kynurenine [187]. 3HKT of An. gambiae has been cloned, expressed, purified, and its biochemical activity and the 3-dimensional (3D) structure determined $[188,189]$. Its inhibition can hamper Plasmodium replication in mosquitoes, since its inhibition prevents XA synthesis needed to trigger exflagellation and maturation of the Plasmodium male gametes [190].

While $3 \mathrm{HKT}$ and KMO could serve as a possible target for malaria transmission-blocking strategies by preventing parasite development in the mosquito, inhibiting these enzymes can negatively affect survival of the mosquitoes. The inhibition of $3 \mathrm{HKT}$ results in the accumulation of 3-hydroxy-L-kynurenine, which could undergo rapid oxidation to form free radicals that can induce apoptosis [189]. Thus, inhibitors of 3HKT may act as both potential insecticides and transmission-blocking agents. $3 \mathrm{HKT}$ has been observed to be the target for 1,2,4-oxadiazole compounds having larvicidal activity against $A e$. aegypti [191, 192]. Since 3HKT of An. gambiae shares $43 \%$ sequence similarity with $3 \mathrm{HKT}$ of Ae. aegypti [188], 1,2,4-oxadiazole compounds could be starting compounds for identification of novel insecticides or transmission-blocking agents. Inhibition of KMO prevents synthesis of 3-hydroxy-L-kynurenine, which is essential for the development of compound eye in mosquito pupa 
stages [185]. Consequently, knockout of this gene will result in mosquito mutants with impaired eye development, since 3-hydroxy-L-kynurenine cannot be produced during the larvae stage. Reports of impaired eye development due to KMO knockout have been reported in Ae. aegypti, with generated mutants having white eye phenotypes [193, 194]. Since compound eye development is completed at the adult stage of mosquitoes, chemical inhibitors of KMO could serve as possible transmissionblocking agents without affecting eye development.

\section{Role of metabolic proteins in fecundity}

Fecundity is a measure of the number of eggs or offspring an organism can produce. This is dependent on egg maturation in the ovaries and oviposition (egg-laying) [195]. Some metabolic proteins (enzymes and transporters) involved in blood digestion and metabolism are upregulated in blood-fed mosquitoes and affect their fecundity [130, 149, 196, 197].

One of such enzymes is phenylalanine-4-hydroxylase (PAH), an enzyme involved in amino acid metabolism, which converts phenylalanine to tyrosine. One isoform of PAH was found to be 3.2-fold over-expressed in blood-fed An. stephensi [130]. This enzyme is important for survival and fecundity in insects [198]. Fuchs et al. [196] reported that knockdown of PAH in An. gambiae reduced the number of eggs laid by the mosquitoes, and impaired the melanization of Plasmodium berghei ookinetes and mosquito eggs. These observations were linked to the unavailability of tyrosine for further metabolism to yield dopamine and melanin after silencing PAH. This was further confirmed by inhibiting another enzyme in the dopamine and melanin synthesis pathway, DOPA decarboxylase (DDC) with Carbidopa. DDC catalyzes the formation of dopamine. Inhibition of DDC yielded the same phenotypes as with PAH silencing [196]. Their study affirms the importance of phenylalanine and tyrosine metabolism in the fecundity of mosquitoes and their immune response to Plasmodium. While PAH might be a potential target for sterilizing strategies through its inhibition, its inhibition will hamper melanization of parasites, consequently, this might increase parasite transmission. This nullifies PAH inhibition as a strategy for vector control. On the other hand, generating mosquitoes' strains with enhanced expression of PAH pbf, might result in mosquitoes with higher fecundity (more eggs) and enhanced immune response (increased melanization). This strategy is promising, if successful, as the refractory mosquitoes would pass on this mutation to their offspring and these mutants will possibly compete well with wild type mosquitoes in nature.

Another enzyme involved in amino acid metabolism, ornithine decarboxylase is encoded by three genes that are upregulated pbf [149]. Ornithine decarboxylase catalyzes the decarboxylation of ornithine to form putrescine [199]. Also, it is important for cell growth because it catalyzes the committed step in polyamines production required for stabilizing newly synthesized DNA [199]. This enzyme is important in fecundity as DNA synthesis and cell cycle are integral processes that accompany egg development and embryogenesis. Inhibition of ornithine decarboxylase using $\alpha$-difluoromethylornithine in $A e$. aegypti resulted in reduced vitellogenin levels, thus negatively affecting fecundity [197]. In addition, increased ornithine decarboxylase pbf led to sequestering of arginine for polyamine synthesis, making it unavailable for nitric oxide synthesis which is needed for immune response to Plasmodium parasites [200]. Thus, inhibiting ornithine decarboxylase would both provide sterilizing strategies as well as result in increased nitric oxide expression for immune response and parasite clearance.

Heme oxygenase, which catalyzes the degradation of heme, also plays a role in fecundity of mosquitoes. Heme is an important component of human blood, which is highly toxic to mosquitoes [201, 202]. Heme oxygenase catalyzes the degradation of heme; thus, it is important for protecting the mosquito from heme toxicity. Approximately $13 \%$ of the heme contained in ingested blood is incorporated into the mosquito as follows: $7 \%$ into tissues of the adult mosquito and 6\% into its eggs [203]. Spencer et al. [6] reported that the consumption of heme oxygenase inhibitors such as zinc protoporphyrin ( $\mathrm{ZnPP})$ and tin protoporphyrin (SnPP) by $A n$. gambiae remarkably decreased egg-laying. They noted that inhibition of heme oxygenase increased sterility by preventing oviposition (laying of eggs), consequently culminating in reduced availability of vectors for malaria transmission [6]. So, the inhibition of heme oxygenase may be further studied for its sterilizing effect for mosquito population suppression.

Similarly, catalase plays a crucial role in regulating fecundity. dsRNA-mediated knockdown of catalase has been observed to significantly reduce the fecundity of $A n$. gambiae mosquitoes [204]. Therefore, catalase may serve as a target for sterilizing strategies. Meanwhile, an $80 \%$ reduction in egg hatching was observed in sterol deficient female houseflies suggesting that sterols are essential for egg hatching [205]. Therefore, transport and metabolism of lipid from a blood diet is crucial in Anopheles reproduction. Vitellogenin is a precursor protein for egg yolk formation, belongs to a family of proteins involved in lipid transport. It is elevated in blood-fed mosquitoes compared to the sugar-fed controls [130]. Since vitellogenin also plays a role in downregulating the anti-plasmodial response in the mosquitoes, it could be inhibited to provide both sterilizing and transmission-blocking strategies. 


\section{Metabolic proteins and vector control using insecticides: the way forward}

To combat the increasing insecticide resistance in mosquitoes, development of new insecticide molecules and combinatorial strategies can be adopted. Identifying novel insecticide targets or taking advantage of unique features in known insecticide targets can help the development of highly selective insecticides. Furthermore, combinatorial strategies may be followed by combining an insecticide with another, with synergists, with sterilants or with transmission-blocking agents in order to slow down resistance and also provide multiple ways of controlling the vector.

\section{Identifying novel insecticide targets}

Following the path to identifying metabolic targets that are (i) crucial for survival in Anopheles species, and (ii) share little or no similarity with other non-target species, developing suitable inhibitors for them will provide a wide array of molecules to replace the classes of insecticides currently being used in malaria control. Previous studies have suggested some metabolic proteins as potential insecticide targets such as carbonic anhydrases, arylalkylamine N-acetyltransferases, V-ATPase, PFK, chorion peroxidase and seven computationally predicted potential insecticide targets [49-52, 206, 207].

Carbonic anhydrases (CAs: EC 4.2.1.1), the enzyme that catalyzes the reversible hydration of carbon dioxide to bicarbonate, has several classes such as $\alpha_{-}, \beta-, \gamma^{-}, \delta_{-}, \zeta_{-}$, $\eta$ - and $\theta$-CAs $[208,209]$. Aside from genes that encode $\alpha$-CAs in An. gambiae, Vullo et al. [52] identified a gene that encodes a $\beta$-CA in An. gambiae, which is absent in vertebrates [210]. In their study, series of anion inhibitors were tested against this metabolic target. Sulphamide, sulphamic acid, phenylboronic acid and phenylarsonic acid successfully inhibited carbonic anhydrase. Although the inhibitors tested were not specific for $\beta$-CAs, their study revealed that specific inhibitors of $\beta$-CAs can be used selectively against invertebrates with minimal toxicity to vertebrates. Recently, famotidine, an antiulcer drug was successfully used to inhibit Anopheles $\beta$-CA with inhibition constant of $397 \mathrm{nM}$ [211]. This particular study is noteworthy since famotidine is safe for humans. Thus, specific Anopheles $\beta$-CA inhibitors that have no toxicity in humans might serve as novel insecticides for malaria control. However, it must be determined if $\beta$-CA is indeed essential for the survival of Anopheles since there are $\alpha$-CAs present that may confer redundancy.

Arylalkylamine N-acetyltransferases (aaNAT, EC 2.3.1.87) catalyze the acetylation of arylalkylamine such as acetylation of dopamine to $\mathrm{N}$-acetyldopamine [212]. These enzymes are necessary in neurotransmitter metabolism and insect cuticle sclerotization [213].
Unlike humans that have one aaNAT, insects have multiple aaNAT, one of which is dopamine $\mathrm{N}$-acetyltransferase (DAT) that is conserved in all insects. However, some aaNAT are insect specific (iaaNAT) and specific for certain genera and substrates, hence they can serve as possible targets for more specific insecticides [214]. O'Flynn et al. [51] revealed that residues that make up the amine binding pocket and the CoA binding pocket of iaaNAT varied among different genera. Their study suggests that these genera specific residues could be exploited to create genus specific insecticides. In previous studies, knockdown of iaaNAT in Bombyx mori and Tribolium castaneum resulted in increased melanin deposition and compromised structural integrity of the exoskeleton [215, 216]. These changes could affect the ability of the insects to mate as well as make them more susceptible to damages from environmental threats [51]. While compromise of structural integrity was recorded in these studies, no direct mortality resulting from inhibition of iaaNAT was reported. Further studies are required to characterize iaaNAT in Anopheles, elucidate the effects of their inhibition and the possibility of these iaaNATs serving as potential insecticide targets.

V-ATPases are proton pumps that hydrolyze ATP and use the energy obtained from the hydrolysis to transport protons across membranes, thus maintaining the intracellular and extracellular $\mathrm{pH}$ of cells [217]. Two insecticidal molecules isolated from plants have been observed to inhibit insect V-ATPases: (i) dihydroagarofuran sesquiterpene polyesters isolates obtained from the root bark of Chinese bittersweet (Celastrus angulatus Max) inhibit subunit $\mathrm{H}$ of V-ATPases [49] (specifically, two of these polyesters, $C V-6-\alpha$-aminopropanoicacid ester and NW70 were highly toxic to Mythimna separata larva with a reported $\mathrm{LD}_{50}$ of 33.605 and $86.271 \mu \mathrm{g} / \mathrm{g}$ ); (ii) a peptide isolate from pea seeds (Pisum sativum), pea albumin 1 subunit $b$ (PA1b) has also been observed to selectively inhibit insect V-ATPases by binding to their $\mathrm{c}$ and $\mathrm{e}$ subunits, so, PA1b was proposed to be a potential insecticide [217]. In a study by Gressent et al. [218], $250 \mu \mathrm{g} /$ $\mathrm{ml}$ of PA1b was added to Cx. pipiens L3 larvae in water, $100 \%$ of the larvae survived after one day and $0 \%$ survival was observed after two days. Also, Ae. aegypti has been reported to be highly sensitive to PA1b [219]. Although both studies were not specific for Anopheles, they are pointers to the possibility of exploiting V-ATPases for vector control strategies. Studies testing these inhibitors in Anopheles and identifying other suitable selective inhibitors of An. gambiae V-ATPases are needed to fully explore and ascertain the possibility of V-ATPases serving as potential insecticide targets. Also, the safety of these molecules to humans must be extensively verified. 
Phosphofructokinase (PFK, EC 2.7.1.11), a key regulatory enzyme, catalyzing the committed step in the glycolytic pathway has been proposed as a potential insecticide target [50]. In the experiments carried out by Nunes et al. [50], it was observed that PFK inhibition by ATP in Ae. aegypti was not enhanced by citrate, and AMP could not relieve ATP inhibition of PFK. Subsequent alignment of several insect PFKs and comparison with non-insect PFKs revealed that PFK in insects including disease vectors Aedes, Anopheles and Culex, have modified citrate and AMP binding sites that distinguish them from their orthologs in non-insect species. Amino acid residues Lys557, Lys617 (a positively charged amino acid) and Thr618 (a neutral amino acid) in citrate binding site of human PFK are substituted by Arg (a positively charged amino acid), Ser or Ala (a neutral amino acid), and Asp or Glu (a negatively charged amino acid), respectively, in all insect sequences examined in their study. In addition, amino acid substitution in AMP binding sites resulted in changes in the overall electrostatic charges of insect PFKs compared to that of humans. These substitutions in AMP and citrate binding sites make PFK in these insects insensitive to regulation by citrate and AMP [50]. Considering the importance of PFK for energy metabolism and consequent survival, these insect unique modifications in PFK could be exploited in disease vectors to produce highly specific and selective insecticides. Further studies evaluating the impact of knockdown of PFK in Anopheles, determining its 3D structure and identifying specific inhibitors are needed.

Computational studies have also helped in the identification of insecticide targets. For instance, Adebiyi et al. [206] employed computational techniques to predict essential metabolic reactions in An. gambiae (consequently, metabolic enzymes) i.e. proteins that are vital for the survival of An. gambiae. Of the 61 enzymes predicted as essential, seven had no homology with humans, tilapia and chicken. Specific inhibitors of these enzymes could serve as novel insecticides, so, future studies can be done to identify suitable inhibitors for these targets. However, one major limitation of the study was the exclusion of transporters that are involved in metabolism, which could be possible insecticide targets. Further computational studies can aid prediction of other potential insecticide targets that can then be confirmed experimentally. Yousafi et al. [207] using computer-aided drug design (CADD) approach to identify alternative insecticides, predicted lead molecules that selectively inhibited insect chorion peroxidase. Their study identified ZINC04581496 and ZINC15675298 as effective lead compounds for chorion peroxidase in Ae. aegypti and An. gambiae, respectively. Although these two compounds were reportedly harmless to humans since they target insect chorion peroxidase, laboratory experiments validating the effect of inhibition of chorion peroxidase on survival in mosquitoes and the suitability of the predicted lead molecules as insecticides are needed.

All the above studies are indicative of the importance of metabolic proteins as insecticide targets. For all the proposed insecticide targets, the development of novel insecticidal molecules can be guided by studies involving (i) knockdown of these proteins and evaluating their effects on Anopheles survival; (ii) comparing protein sequence and structure to determine organism specificity and identifying unique features in targets that can be manipulated; and (iii) 3D structural elucidation of confirmed potential targets, virtual screening and identification of lead compounds.

\section{Generation of organism-target specific and selective insecticides}

Generation of organism-target specific and selective insecticides involves taking advantage of unique features in insecticide targets. This is highly dependent on the structural elucidation of insecticide targets and creation of more target specific inhibitors. This is important for both newly identified and already known insecticide targets, thus providing insecticides that are less toxic to non-target species. For example, structural elucidation of AgAChE revealed an unpaired cysteine (Cys), Cys447, which is absent in hAChE [25]. However, protein sequences of 13 animal species were analyzed for the conservation of this unpaired cysteine residue using Clustal Omega on EMBL-EBI's multiple sequence alignment platform. The result showed that this cysteine residue is conserved in some of the disease vectors, namely, An. gambiae, An. sinensis, Ae. aegypti and Cx. pipiens, but absent in non-target species such as humans and birds that have other amino acid residues substituted at this position instead (Fig. 4). Although this residue is not conserved in An. stephensi, it could be utilized for selective targeting of An. gambiae and other disease vectors. A recent study tested some selected AChE cysteinetargeted insecticides (succinimide or maleimide compounds) on AgAChE and hAChE and found that all the tested compounds inhibited both enzymes irreversibly, showing poor selectivity [220]. Although the study did not support the concept of selectively targeting AgAChE by taking advantage of the unique cysteine residue, some older studies supported the cysteine-targeted selective inhibition of AgAChE. For example, Pang et al. [221] noted that $6 \mu \mathrm{M}$ of a methanethiosulfonate-containing molecule had $95 \%$ inhibition on AgAChE and $>80 \%$ on Ae. aegypti and $C x$. pipiens in approximately $30 \mathrm{~min}$ utes, while it partially inhibited hAChE after a prolonged exposure of 4 hours [221]. While their study suggests 
that rapid selective inhibition of AgAChE is possible, the potential hazards associated with prolonged exposure to this molecule is questionable. Dou et al. [222] observed that two maleimide compounds, PMn and PYn selectively and irreversibly inhibited AgAChE but spared that of humans. These studies indicate that species-specific or unique features in insecticide targets could be manipulated for targeted vector control. However, the concept of selective cysteine-targeted inhibition should be further studied and explored to enable the design of new compounds that will selectively and specifically inhibit AgAChE with no toxicity to non-target species especially humans.

Asides exploiting unique features in targets for insecticide design, understanding the mechanism by which mutations in current insecticide targets reduce their binding affinity for the corresponding insecticide is needed. This may give insight into ways by which current insecticides can be chemically modified to overcome insensitivity to these targets. For instance, new carbamate derivatives synthesized via chemical substitutions on aryl carbamates and pyrazol-4-yl methylcarbamates displayed increased toxicity to insecticide-resistant $A n$. gambiae and were highly selective for AgAChE compared to hAChE [48]. In addition, PyrimidineTrione Furan-substituted (PTF) compounds have been observed to preferentially bind mutated G119S AChE [223]. Knutsson et al. [224] designed, synthesized and evaluated the biological activity of phenoxyacetamide-based inhibitors of AgAChE and observed that these inhibitors were highly selective for AgAChE compared to hAChE. Also, these inhibitors were effective towards AgAChE with G119S mutation. These studies are pointers to the possibility of chemically modifying current insecticides and developing more species-specific insecticides.

\section{Combining two or more insecticidal agents in a single product}

The concept of having a cocktail of inhibitors in a single insecticide product may slow down the development of insecticidal resistance and be beneficial in killing resistant mosquitoes. An example of this was described in a study that mixed organophosphate and pyrethroid insecticides to obtain a combination that was effective in killing mosquitoes with resistant alleles [225]. Moreover, a new ITN, Interceptor ${ }^{\circledR}$ G2 having a mixture of chlorfenapyr and alphacypermethrin was tested and compared with Interceptor ${ }^{\circledR}$ having only alphacypermethrin and a chlorfenapyr-only net against pyrethroid-resistant $A n$. gambiae in experimental field huts [226]. While alphacypermethrin is a pyrethroid insecticide exerting its actions by modulating sodium channels, chlorfenapyr is a pyrrole insecticide that uncouples oxidative phosphorylation thereby preventing ATP synthesis [227]. Camara et al. [226] noted that Interceptor ${ }^{\circledR}$ G2 whether unwashed or washed 20 times significantly killed the mosquitoes by $87 \%$ and $82 \%$, respectively, compared to Interceptor ${ }^{\circledR}$ washed or unwashed which resulted in only $10 \%$ mortality, while the use of nets treated with chlorfenapyronly resulted in $92 \%$ mortality. Also, Interceptor ${ }^{\circledR}$ G2 unwashed or washed 20 times and chlorfenapyr-only nets greatly inhibited blood-feeding by $42 \%, 34 \%$ and $54 \%$, respectively, unlike Interceptor ${ }^{\circledR}$ which had no significant effect on blood-feeding compared to untreated nets [226]. Additionally, Interceptor ${ }^{\circledR}$ G2 met World Health Organization Pesticide Evaluation Scheme (WHOPES) criteria for further testing and evaluation in phase III study. The mortality rates reported in their study corroborates a previous study, which compared the effect of nets treated with a mixture of chlorfenapyr and alphacypermethrin to those treated with chlorfenapyr only and alphacypermethrin only on mosquito survival [228].

In the study of N'Guessan et al. [228], nets treated with insecticide mixture significantly killed mosquitoes compared to alphacypermethrin-only treated nets (77 vs $30 \%)$ and they did not differ significantly from nets treated with chlorfenapyr only (69\%). Meanwhile, nets with insecticide mixture induced a higher blood-feeding inhibition on mosquitoes compared to nets treated with alphacypermethrin only (35-51 vs $22 \%$ ), while no blood-feeding inhibition was evident for nets treated with chlorfenapyr [228]. While both studies affirmed that chlorfenapyr was important for killing pyrethroid-resistant mosquitoes, they did not agree on the contributions of alphacypermethrin and chlorfenapyr to blood-feeding inhibition. The effect of alphacypermethrin on bloodfeeding inhibition was suggested by a different study in which ITNs with alphacypermethrin only (MiraNet and MagNet) greatly inhibited blood-feeding compared to untreated nets, despite that it had only limited mortality effect compared to untreated nets [229]. The observed differences in blood-feeding inhibition with alphacypermethrin-only nets in different studies might be due to differences in pyrethroid resistance intensity in the various study areas (Table 2). Despite the differences in blood-feeding inhibition, alphacypermethrin still offers personal protection against mosquito bite. This suggests that alphacypermethrin continues to provide some level of protection even in areas with high pyrethroid resistance intensity. Similar to the study of Camara et al. [226], some other studies suggested that chlorfenapyr also inhibits blood-feeding in mosquitoes. For example, N'Guessan et al. [230] showed that Interceptor ${ }^{\circledR}$ G2, Interceptor ${ }^{\circledR}$ and chlorfenapyr inhibited blood-feeding by $60 \%, 43 \%$ and $57 \%$, respectively. Similarly, in a study on An. arabiensis, a blood-feeding inhibition of $76 \%$, 


1. P07140|ACES_DROME
2. P56161|ACES_ANOST
3. P38433|ACE1_CAEEL
4. Q86GC8|ACES_CULPI
5. Q6A2E2 | Q6A2E 2_AEDAE
6. Q869C3 |ACES_ANOGA
7. A0A1D8X953|A0A1D8X953_ANOSI
8. P04058|ACES_TETCE
9. P36196|ACES_CHICK
10. P21836|ACES_MOUSE
11. P37136|ACES_RAT
12. P22303|ACES_HUMAN
13. P23795|ACES_BOVIN

Fig. 4 Conserved unpaired cysteine residue in the

acetylcholinesterase (AChE) of disease vectors for selective insecticide design. The sequences shown are from Drosophila melanogaster (DROME), Tetronarce californica (TETCF), Mus musculus (MOUSE), Homo sapiens (HUMAN), Bos taurus (BOVIN), Rattus norvegicus (RAT), Caenorhabditis elegans (CAEEL), Anopheles stephensi (ANOST), An. gambiae (ANOGA), Culex pipiens (CULPI), An. sinensis (ANOSI), Aedes aegypti (AEDAE). The name of each organism starts with its UniProt accession number. The black arrow points to the position of the conserved unpaired cysteine residue. The unpaired cysteine residue is conserved in disease vectors (4-7). This residue is substituted by a leucine residue in An. stephensi and Drosophila AChE (1-2), phenylalanine residues in mammals, fish and bird AChE (8-13), and a glycine residue in nematode AChE (3). This unpaired cysteine could be targeted for the development of more selective and specific insecticides. * indicates positions that have single and conserved amino acid residues; : indicates conservation between amino acid residues of strongly similar properties; . indicates conservation between amino acid residues of weakly similar properties

$52 \%$ and $72 \%$ was observed for nets treated with the mixture, alphacypermethrin only and chlorfenapyr only, respectively [231]. Both studies provided evidence that alphacypermethrin and chlorfenapyr, each inhibit the blood-feeding of mosquitoes. Interceptor ${ }^{\circledR} \mathrm{G} 2$ may be a replacement for currently available ITNs, thus contributing to the reduction of malaria transmission, considering the increased mortality with their use, and their wash durability (washing Interceptor ${ }^{\circledR}$ G2 only reduced killing efficacy by $2-6 \%$ ) (Table 2 ). Although most studies show that mortality rates of mosquitoes did not differ significantly between nets treated with alphacypermethrin and chlorfenapyr mixture and those treated with chlorfenapyr only, combining the insecticides might enhance bloodfeeding inhibition and personal protection against bites. Thus, these studies suggested that combining insecticides in a single product could be effective in killing insecticide resistant mosquitoes and reducing their blood-feeding propensity. Further combination of this kind can effectively kill insecticide-resistant mosquitoes and slow down the emergence of insecticide resistance.

\section{Combining insecticide with synergists}

Another option is the combination of current insecticides with inhibitors to their known detoxifying enzymes.
Since oxidative defense greatly impacts insecticide resistance and inhibition of some enzymes involved in oxidative defense increases the sensitivity of the mosquito to insecticide, they can be exploited for development of novel insecticides [232]. Potent insecticide molecules can be combined with inhibitors of detoxification enzymes such as CYP450, GSTs to greatly reduce insecticide resistance. These inhibitor molecules are referred to as synergists. Synergists are chemicals that inhibit metabolic enzymes involved in insecticide detoxification, thereupon allowing the insecticide more time to work, e.g. piperonyl butoxide (PBO) [23]. A practical example of the effect of combining insecticides with synergists, is the increased pyrethroid-susceptibility that was observed when pyrethroids were combined with PBO [23]. In a study by Ketoh et al. [233], higher mortality rates and reduced blood-feeding were observed in mosquitoes that were exposed to pyrethroid-treated nets with $\mathrm{PBO}$ compared to those exposed to pyrethroid only treated nets. PBO inhibits cytochrome P450 enzymes, which are key players in insecticide resistance, it also increases cuticular penetration of insecticides [233]. Different pyrethroids have been combined with PBO in ITNs and have been tested for their efficacies in diverse studies. Examples include PermaNet 3.0 (deltamethrin + PBO) [234-236], Olyset ${ }^{\circledR}$ Plus (Permethrin + PBO) $[237,238]$. In all these studies, these nets with synergists had higher mortality rates on mosquitoes compared to exposure to their respective insecticide only treated nets, PermaNet 2.0 (deltamethrin only) and Olyset (permethrin only) (Table 3).

Recently, Oumbouke et al. [239] reported that the use of VEERALIN ${ }^{\circledR}$ nets, an alphacypermethrin PBO synergist net, resulted in a higher mortality rate of mosquitoes (51 vs 29\%) and a greater inhibition on blood-feeding (62.6 vs $35.4 \%$ ) compared to MagNet, an alphacypermethrin-only net. The study suggests that PBO does not only reduce resistance to pyrethroid but, also, potentiates the blood-feeding inhibitory effect of pyrethroids. Meanwhile, loss of efficacy to pyrethroid-based ITNs including Olyset ${ }^{\circledR}$ Plus (low mortality rates of mosquitoes) in An. funestus has been reported [240]. These low mortality rates might be due to pyrethroid resistance intensity in study areas as observed in a different study by Corbel et al. [235]. In their study, the study area with the highest pyrethroid resistance intensity had the lowest mortality rate from use of PermaNet 3.0. While this low mortality rate from pyrethroid and synergist-based nets is alarming, these nets still offer a high level of personal protection from mosquito bite (Table 3). Therefore, combining pyrethroid $+\mathrm{PBO}$ with an insecticide having a different mode of action for use in ITNs may be advantageous. For example, combining chlorfenapyr, alphacypermethrin 
and $\mathrm{PBO}$ in a single insecticide product may provide a greater advantage by killing pyrethroid-resistant mosquitoes and inhibiting blood-feeding propensity at a higher level. Furthermore, the loss of efficacy to pyrethroidbased ITNs may be due to other resistant mechanisms not addressed by PBO (a cytochrome P450 inhibitor) such as metabolic resistance due to GSTs. Menze et al. [238] observed that An. funestus resistant to Olyset or Olyset ${ }^{\circledR}$ Plus due to L119F-GSTe2 mutation had a greater blood-feeding rate compared to mosquitoes with L119 susceptible allele. This mutation was also associated with increased exophily. Consequently, increased bloodfeeding rates may greatly enhance the chances of malaria transmission and increased exophily would make the mosquitoes avoid insecticides. Also, their study reported the inability of the synergist, $\mathrm{PBO}$, to prevent metabolic resistance due to GSTs. As a result, incorporating GSTs inhibitors such as diethyl maleate into insecticidal products can reduce insecticide resistance and malaria transmission [238]. Therefore, combining chlorfenapyr, alphacypermethrin (or other pyrethroids), PBO and diethyl maleate (or any other potent GST inhibitor) in a single product may provide an insecticide with better efficacy.

The maintenance of redox homeostasis in Anopheles impacts its innate immune response to Plasmodium, its survival or longevity as well as its detoxification capacity and consequently its susceptibility to insecticides

Table 2 Efficacy of alphacypermethrin and chlorfenapyr mixture in insecticide treated nets

\begin{tabular}{|c|c|c|c|c|c|c|c|c|}
\hline \multicolumn{3}{|l|}{ Reference } & $\begin{array}{l}\text { Camara et al. } \\
{[226]}\end{array}$ & Bayili et al. [269] & $\begin{array}{l}\text { N'Guessan et al. } \\
\text { [230] }\end{array}$ & \multicolumn{2}{|c|}{ N’Guessan et al. [228] } & $\begin{array}{l}\text { Oxborough et al. } \\
\text { [231] }\end{array}$ \\
\hline \multicolumn{3}{|c|}{ Mosquito strain \& (location) } & $\begin{array}{c}\text { An. gambiae } \\
\text { (s.s.) (Côte } \\
\text { d'lvoire) }\end{array}$ & $\begin{array}{l}\text { An. gambiae } \\
\text { (s.I.) (Burkina } \\
\text { Faso) }\end{array}$ & $\begin{array}{l}\text { An.gambiae } \\
\text { (s.l.) (Benin) }\end{array}$ & \multicolumn{2}{|c|}{$\begin{array}{l}\text { An. gambiae (s.l.) } \\
\text { (Benin) }\end{array}$} & $\begin{array}{l}\text { An. arabiensis } \\
\text { (Tanzania) }\end{array}$ \\
\hline \multicolumn{3}{|c|}{ Pyrethroid resistance intensity (folds) } & $\begin{array}{l}450.2 \text { (for } \\
\text { Alpha). Over } \\
1700 \text { (for del- } \\
\text { tamethrin) }\end{array}$ & Over 1000 & 207 (for Alpha) & \multicolumn{2}{|l|}{207} & \\
\hline \multirow[t]{3}{*}{ Insecticide } & \multicolumn{2}{|l|}{ Alpha $\left(\mathrm{mg} / \mathrm{m}^{2}\right)$} & $\begin{array}{l}200 \text { on Inter- } \\
\text { ceptor }^{\circledR}\end{array}$ & $\begin{array}{l}200 \text { on Inter- } \\
\text { ceptor }^{\circledR}\end{array}$ & $\begin{array}{l}200 \text { on Inter- } \\
\text { ceptor }^{\circledR}\end{array}$ & \multicolumn{2}{|l|}{25} & 25 \\
\hline & \multicolumn{2}{|c|}{$\operatorname{CFP}\left(\mathrm{mg} / \mathrm{m}^{2}\right)$} & 200 & 200 & 200 & \multicolumn{2}{|l|}{200} & 100 \\
\hline & \multicolumn{2}{|c|}{ Alpha + CFP $\left(\mathrm{mg} / \mathrm{m}^{2}\right)$} & $\begin{array}{l}100+200 \text { on } \\
\text { Interceptor }^{\circledR} \\
\text { G2 }\end{array}$ & $\begin{array}{l}100+200 \text { on } \\
\text { Interceptor }^{\circledR} \\
\text { G2 }\end{array}$ & $\begin{array}{l}100+200 \text { on } \\
\text { Interceptor }^{\circledR} \\
\text { G2 }\end{array}$ & $25+100$ & $25+200$ & $25+100$ \\
\hline \multirow{5}{*}{$\begin{array}{l}\text { Mortality at } 72 \\
h^{\#}(\%)\end{array}$} & \multirow[t]{2}{*}{ Alpha } & Unwashed & $10^{\mathrm{a}}$ & 17 & 20 & \multicolumn{2}{|l|}{30} & $50^{f}$ \\
\hline & & $\begin{array}{l}\text { Washed } 20 \\
\text { times }\end{array}$ & $11^{\mathrm{a}}$ & 10 & 13 & \multicolumn{2}{|l|}{ nd } & nd \\
\hline & \multicolumn{2}{|l|}{ CFP } & $92^{b}$ & $86^{d}$ & 76 & \multicolumn{2}{|l|}{$69^{e}$} & $48^{f}$ \\
\hline & \multirow[t]{2}{*}{ Alpha + CFP } & Unwashed & $87^{b, c}$ & $78^{d}$ & 71 & $75^{e}$ & $77^{e}$ & $58^{f}$ \\
\hline & & $\begin{array}{l}\text { Washed } 20 \\
\text { times }\end{array}$ & $82^{c}$ & $76^{d}$ & 65 & nd & nd & nd \\
\hline \multirow{5}{*}{$\begin{array}{l}\text { Blood-feeding } \\
\text { inhibition"\#\# } \\
(\%)\end{array}$} & \multirow[t]{2}{*}{ Alpha } & Unwashed & ns & $26^{a, b, c}$ & $57^{d}$ & \multicolumn{2}{|l|}{$22^{f}$} & $52^{g}$ \\
\hline & & $\begin{array}{l}\text { Washed } 20 \\
\text { times }\end{array}$ & ns & $15^{a}$ & $47^{e}$ & \multicolumn{2}{|l|}{ nd } & nd \\
\hline & \multicolumn{2}{|l|}{ CFP } & 54 & $21^{a, c}$ & $43^{e}$ & \multicolumn{2}{|l|}{ ns } & $72^{g}$ \\
\hline & \multirow[t]{2}{*}{ Alpha + CFP } & Unwashed & 43 & $42^{b}$ & $60^{d}$ & 51 & $35^{f}$ & $76^{9}$ \\
\hline & & $\begin{array}{l}\text { Washed } 20 \\
\text { times }\end{array}$ & 34 & $32^{b, c}$ & $50^{\mathrm{d}, \mathrm{e}}$ & nd & nd & nd \\
\hline \multirow{5}{*}{$\begin{array}{l}\text { Personal } \\
\text { protection \#\# } \\
(\%)\end{array}$} & \multirow[t]{2}{*}{ Alpha } & Unwashed & $57^{a, c}$ & $24^{d}$ & $62.5^{\mathrm{e}}$ & \multicolumn{2}{|l|}{39} & nd \\
\hline & & $\begin{array}{l}\text { Washed } 20 \\
\text { times }\end{array}$ & $47^{c}$ & $14^{d}$ & $22^{f}$ & \multicolumn{2}{|l|}{ nd } & nd \\
\hline & \multicolumn{2}{|l|}{ CFP } & $76^{b}$ & $22^{d}$ & $36.7^{9}$ & \multicolumn{2}{|l|}{23} & nd \\
\hline & \multirow[t]{2}{*}{ Alpha + CFP } & Unwashed & $71^{a, b}$ & $44^{d}$ & $59.2^{\mathrm{e}}$ & 62 & 58 & nd \\
\hline & & $\begin{array}{l}\text { Washed } 20 \\
\text { times }\end{array}$ & $60^{a}$ & $34^{d}$ & $34.4^{\mathrm{f}, \mathrm{g}}$ & nd & nd & nd \\
\hline
\end{tabular}


$[145,165,232]$. NADPH-dependent reducing capacity is a key contributor to the maintenance of redox homeostasis; hence, NADPH concentration is increased during ROS generation. Manipulation of NADPH pools was suggested to affect fecundity and insecticide detoxification capacity of An. gambiae [145]. Combining potent insecticide molecules with modulators that can diminish NADPH pools during insecticide application would result in more potent insecticides as insecticide resistance will be greatly reduced.

Combining insecticides with transmission-blocking agents In a recent study by Paton et al. [241], An. gambiae mosquitoes were exposed to atovaquone (ATQ, an antimalarial which targets the cytochrome b of Plasmodium) and other cytochrome $b$ inhibitors such as acequinocyl (ACE) and hydramethylnon (HYD). Exposure to ATQ, HYD and ACE reduced oocyst prevalence by $100 \%, 63.9 \%$ and $64.3 \%$, respectively, relative to controls. As such, exposure of An. gambiae mosquitoes to these compounds before $P$. falciparum infection greatly aborted parasite development upon infection. Their study suggests that these cytochrome $b$ inhibitors are suitable agents for transmission-blocking strategies in mosquitoes, as a result preventing malaria transmission. Therefore, combining insecticidal inhibitors of Anopheles metabolic proteins with inhibitors of Plasmodium metabolic protein (having anti-plasmodial activity) in ITNs or insecticidal spray can serve as a suitable vector control strategy. This combination will prevent transmission by two strategies, either causing mortality of mosquitoes or blocking parasite transmission by clearing the parasite from the midgut of mosquito.

Anopheles metabolic proteins can serve as candidates for transmission-blocking vaccines (TBV). For example, amino-peptidase $\mathrm{N} 1$ protein (APN) from mosquito midgut was observed to be an antigen that could be targeted by antibodies to prevent Plasmodium parasite development. Hence, it has been proposed as a leading TBV candidate [242]. Exposure of mosquitoes to anopheline APN (AnAPN1) monoclonal antibodies efficiently blocked parasite transmission in a dose dependent manner [243].

In addition, the concept of smart sprays has been previously described as chemicals that disrupt interactions that support parasite development, or those that enhance interactions that antagonize parasite development [244]. Therefore, combining insecticides with inhibitors of other metabolic proteins involved in parasite development such as aquaporin 3, trehalose transporter, catalase, $\mathrm{KMO}, 3 \mathrm{HKT}$, etc., could yield vector control strategies in which resistant mosquitoes that escape insecticides would be unable to transmit malaria due to the action of TBAs. However, inhibition of these proteins must be highly specific for target species.

\section{Combining insecticides with sterilants}

Mitchell \& Catteruccia [245] proposed the combination of insecticides with sterilants. With this combination, resistant mosquitoes that escape insecticides would have no progeny due to the sterilant and would not be able to pass their resistance to their progenitors. For instance, combining insecticides with zinc protoporphyrin (ZnPP) and tin protoporphyrin $(\mathrm{SnPP})$, that are inhibitors of heme oxygenase in a single product may offer an advantage of reduced egg-laying in mosquitoes that escape the killing effect of the insecticides. Nevertheless, the safety of these molecules to non-target species must be duly considered. More species-specific heme oxygenase inhibitors may be developed by taking advantage of possible unique features that may be present in anopheline heme oxygenase and absent in non-target species. These inhibitors may serve as sterilants and be used in combination with insecticides.

Whatever method is applied in the development of novel insecticides, the safety to non-target species especially humans must be duly considered. Figure 5 shows a schematic representation, summarizing the various ways metabolic proteins of Anopheles could be manipulated for vector control strategies. In addition, the role of some Anopheles metabolic proteins in malaria transmission and prevention, as well as the possible intervention strategies that can be achieved by targeting these proteins is shown in Table 4.

\section{Vector control strategies: genetic modification of metabolism for population replacement or suppression}

Population replacement involves substituting Plasmodium-susceptible mosquitoes in the wild with laboratory-generated species that are refractory to the parasite, hence incapable of transmitting malaria [246]. This is hinged on genetic modification of the innate immune response of Anopheles for enhanced clearance of the parasite. Metabolic proteins that positively regulate the immune response such as NOS, CLIPA8, PO can be genetically modified to increase expression upon bloodfeeding. This will ultimately enhance parasite clearance, which will consequently reduce transmission. A study comparing NOS levels in vector and non-vector An. culicifacies (i.e. those capable of transmitting disease and those that cannot, respectively) established that elevated midgut levels of inducible NOS upon ingestion of a Plasmodium infected blood meal results in effective parasite clearance in non-vector species compared to vector species [247]. Also, inhibition of NOS activity in 


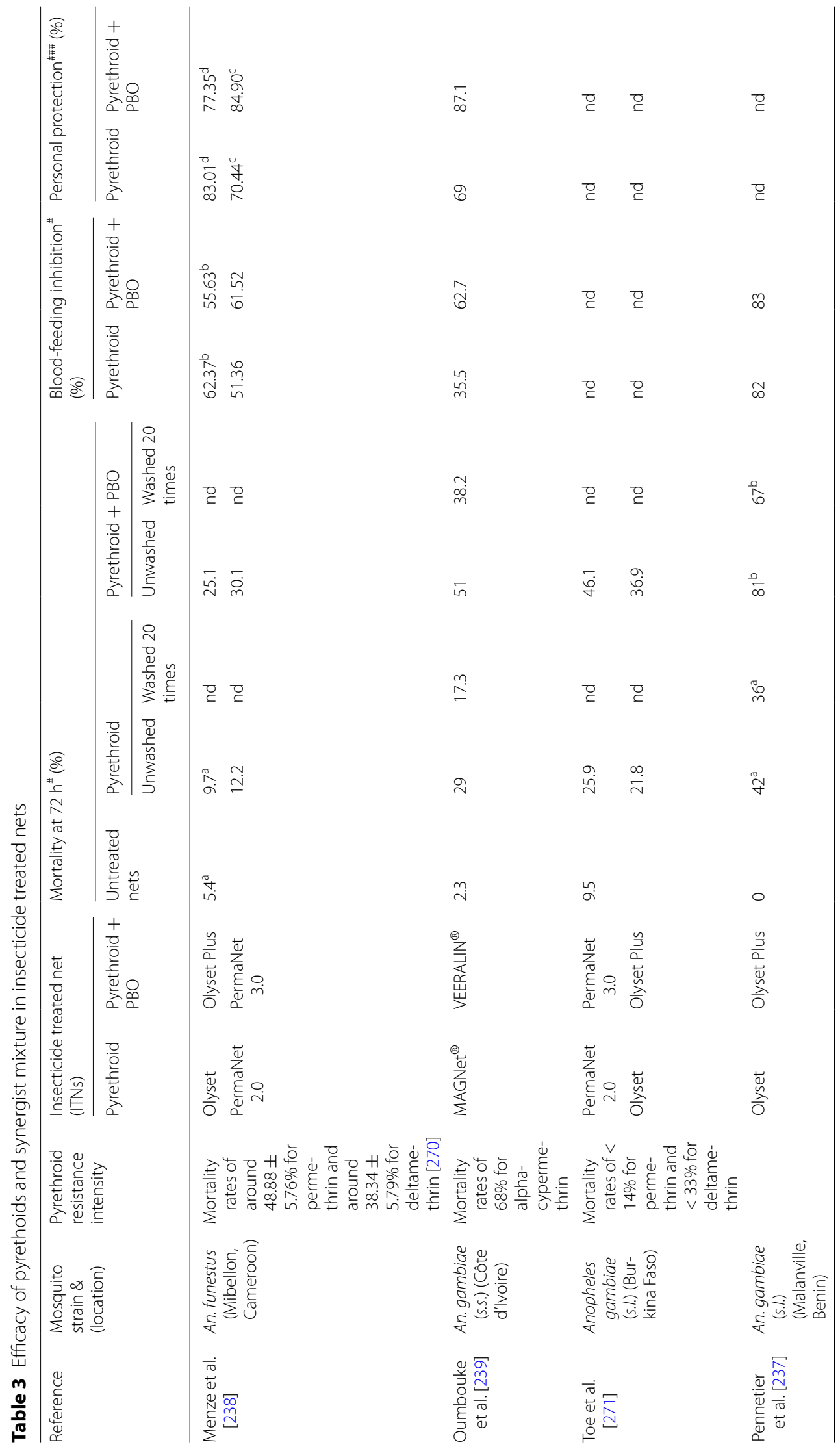




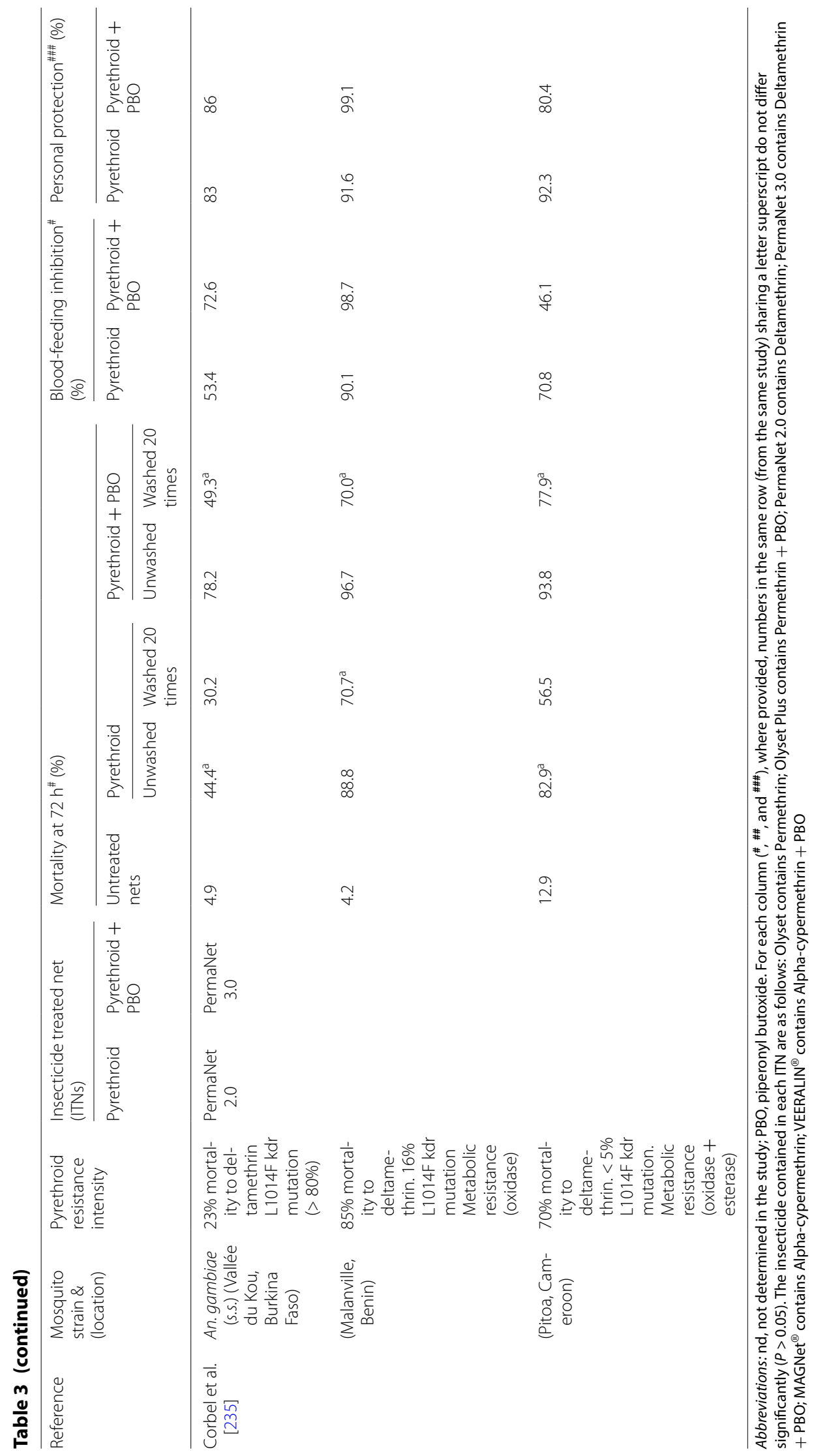




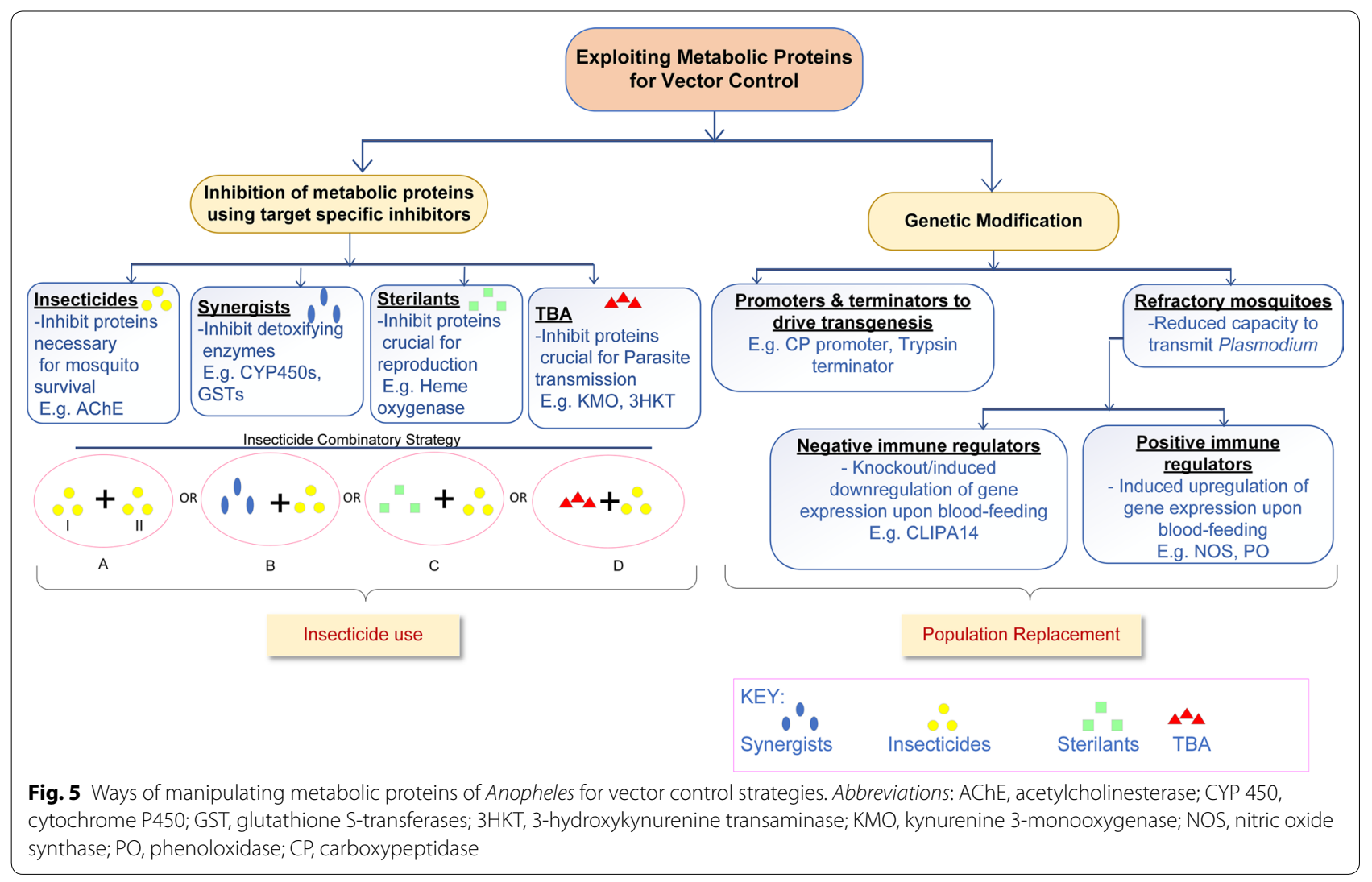

non-vector species resulted in increased oocyte levels in the mosquito. This study suggests that genetic modification to enhance inducible NOS expression upon bloodfeeding can aid parasite clearance and reduce malaria transmission.

Apart from increasing expression of metabolic proteins that positively regulate the immune response, the promoters of some metabolic proteins are significantly activated in specific tissues during a blood meal, e.g. the activation of the carboxypeptidase promoter in the midgut [248] or vitellogenin in the fat tissues [249]. They were induced pbf while apyrase was constitutively expressed in the saliva [250]. These promoters, together with a trypsin terminator, have been used in different studies to drive expression of transgenes [249, 251]. Thus, these promoters and terminator may be used to drive tissue-specific expression of transgenes in Anopheles for enhanced immune response and parasite clearance, thereby reducing malaria transmission.

Population suppression involves reducing mosquito population, thereby making them unavailable for malaria transmission. This involves employing genetic techniques to generate a sterile mosquito population. Many metabolic proteins such as heme oxidase or catalase are essential for both fecundity and oviposition. However, these proteins are also essential for the survival and development of mosquitoes. Thus, knockout of these metabolic proteins may induce sterility but will attract a fitness cost making such genetic manipulations unsustainable. As a result, for most population suppression studies, male mosquitoes are made sterile and consequently cannot fertilize the female mosquitoes [252]. To the best of our knowledge, no metabolic protein has been genetically manipulated for the generation of sterile mosquitoes.

Whatever genetic modification is being carried out, fitness cost to the mosquito must be duly considered as the genetically modified mosquitoes must be able to outcompete the wild type.

\section{Conclusions}

Anopheles metabolic proteins immensely contribute to the survival of the mosquito and development of Plasmodium in the mosquito, and consequently, to malaria transmission. They can be manipulated for vector control strategies. Specific and selective inhibitors can be developed for potential insecticide targets by taking advantage of unique features in targets, thus preventing toxicity to non-target species. Inhibitors discovered to have high insecticidal activity could be used in combinations to slow down the development of resistance to 
Table 4 Possible Anopheles' metabolic proteins for vector control strategies based on their role in malaria transmission

\begin{tabular}{|c|c|c|}
\hline Role in malaria transmission & Metabolic protein & Possible intervention strategy \\
\hline \multirow[t]{2}{*}{ Destruction of Plasmodium ookinetes } & Chymotrypsin ${ }^{\mathrm{a}}[136]$ & \multirow{2}{*}{$\begin{array}{l}\text { Genetic modification: development of refractory } \\
\text { mosquitoes with enhanced expression of proteins } \\
\text { post blood-feeding. Prevention of peritrophic } \\
\text { membrane development }\end{array}$} \\
\hline & Trypsin $^{\mathrm{a}}[135,136]$ & \\
\hline \multirow{2}{*}{ Enhances immune response to Plasmodium parasite } & Phenylalanine-4-hydroxylase ${ }^{a}$ (PAH) [196] & \multirow{2}{*}{$\begin{array}{l}\text { Genetic modification: development of refractory } \\
\text { mosquitoes with increased expression of proteins } \\
\text { post blood-feeding }\end{array}$} \\
\hline & Nitric oxide synthase ${ }^{b}$ (NOS) $[170,172]$ & \\
\hline \multirow{10}{*}{$\begin{array}{l}\text { Enhances Plasmodium parasite development or } \\
\text { negative regulator of immune response }\end{array}$} & Carboxypeptidase $^{a}[143]$ & \multirow{10}{*}{$\begin{array}{l}\text { Transmission-blocking agents: inhibition of proteins } \\
\text { provides transmission-blocking strategies. } \\
\text { Carboxypeptidase can be already targeted using } \\
\text { antibodies [143] }\end{array}$} \\
\hline & Kynurenine 3-monooxygenase ${ }^{a}[179]$ & \\
\hline & 3-hydroxykynurenine transaminase ${ }^{\mathrm{a}}$ [189] & \\
\hline & Ornithine decarboxylase ${ }^{a}[200]$ & \\
\hline & Aquaporin $3[178]$ & \\
\hline & Trehalose transporter ${ }^{\mathrm{C}}[177]$ & \\
\hline & Catalase $^{b}[158]$ & \\
\hline & Vitellogenin $^{d}[5]$ & \\
\hline & Lipophorin $^{d}[5]$ & \\
\hline & Apolipophorin ${ }^{d}[181,182]$ & \\
\hline \multirow[t]{5}{*}{ Fecundity } & Phenylalanine-4-hydroxylase $(\mathrm{PAH})^{\mathrm{a}}[196]$ & \multirow[t]{5}{*}{ Sterilants: inhibition may offer sterilizing strategies } \\
\hline & Ornithine decarboxylase $e^{\mathrm{a}}[197]$ & \\
\hline & Heme oxygenase [6] & \\
\hline & Vitellogenin $^{d}[5]$ & \\
\hline & Catalase $^{b}[204]$ & \\
\hline \multirow[t]{3}{*}{ Energy production during flight } & Trehalase ${ }^{c}[156]$ & \multirow{3}{*}{$\begin{array}{l}\text { Flight inhibitors: inhibition may provide flight inhibi- } \\
\text { tion strategies }\end{array}$} \\
\hline & Pyrroline-5-carboxylate reductase ${ }^{a}[144]$ & \\
\hline & Proline oxidase ${ }^{a}[144]$ & \\
\hline \multirow[t]{2}{*}{ Insecticide resistance } & Cytochrome P450 monooxygenases ${ }^{\mathrm{e}}$ [238] & \multirow{2}{*}{$\begin{array}{l}\text { Synergists: inhibitors may reverse insecticide resist- } \\
\text { ance }\end{array}$} \\
\hline & Glutathione S-transferases ${ }^{e}[238]$ & \\
\hline \multirow[t]{8}{*}{ Survival or development of mosquitoes } & Aquaporin $3[178]$ & \multirow[t]{8}{*}{ Insecticides: inhibitors may act as insecticides } \\
\hline & Catalase $^{\mathrm{b}}[159]$ & \\
\hline & 3-hydroxykynurenine transaminase ${ }^{a}[189]$ & \\
\hline & Carbonic anhydrase [52] & \\
\hline & Arylalkylamine N-acetyltransferases [51] & \\
\hline & Chorion peroxidase [207] & \\
\hline & V-ATPases $[218,219]$ & \\
\hline & Phosphofructokinase $[50]$ & \\
\hline
\end{tabular}

\footnotetext{
a Protein involved in protein/amino acid metabolism

${ }^{b}$ Protein involved in metabolism of reactive oxygen species

c Protein involved in carbohydrate metabolism

d Protein involved in lipid metabolism

e Protein involved in xenobiotic metabolism
}

these compounds. Also, these insecticides can be used in combination with synergists, sterilants or TBAs. Likewise, other metabolic proteins that are involved in immune response can be manipulated to produce genetically modified mosquitoes, which are refractory to Plasmodium, thereby replacing the susceptible population of mosquitoes. However, the modified species should be able to out-compete the wild-type in nature. Besides this, the safety of genetically-modified strains to the ecosystem must be duly considered. With all these issues considered and put in the right perspective, metabolic proteins of Anopheles provide a repertoire for various interventions that would go a long way in curbing malaria transmission. 


\section{Supplementary information}

Supplementary information accompanies this paper at https://doi. org/10.1186/s13071-020-04342-5.

Additional file 1: Figure S1. Alignment of the amino acid sequences of AChE from 13 animal species: Drosophila melanogaster (DROME), Tetronarce californica (TETCF), Mus musculus (MOUSE). Homo sapiens (HUMAN), Bos taurus (BOVIN), Rattus norvegicus (RAT), Caenorhabditis elegans (CAEEL), Anopheles stephensi (ANOST), An. gambiae (ANOGA), Culex pipiens (CULPI), An. sinensis (ANOSI) and Aedes aegypti (AEDAE). The positions of the conserved unpaired cysteine and catalytic serine are indicated by a black arrow. The catalytic serine residue is conserved in all the animals. The unpaired cysteine residue is conserved in disease vectors (4-7). This residue is substituted by a leucine residue in An. stephensi and Drosophila AChE (1-2), phenylalanine residues in mammals, fish and bird AChE (8-13), and a glycine residue in nematode AChE (3). * indicates positions that have single and conserved amino acid residues; : indicates conservation between amino acid residues of strongly similar properties; indicates conservation between amino acid residues of weakly similar properties.

\section{Abbreviations}

ITNs: insecticide-treated nets; IRS: indoor residual spraying; WHO: World Health Organization; PAH: phenylalanine-4-hydroxylase; AChE: acetylcholinesterase; hAChE: human acetylcholinesterase; AgAChE: An. gambiae acetylcholinesterase; CYP 450: cytochrome P450; CEs: carboxylesterases; AQP3: aquaporin 3; GSTs: glutathione S-transferases; HPX2: heme peroxidase 2; NOX5: NADPH oxidase 5; NOS: nitric oxide synthase; PO: phenoloxidase; TreT1: trehalose transporter; KMO: kynurenine 3-monooxygenase; PFK: phosphofructokinase; ABC: ATP-binding cassette; GWAS: genome-wide association studies; pbf: post-blood-feeding; CP: carboxypeptidase; INS: insecticide; SYN: synergist; STER: sterilant; TBA: transmission-blocking agent; GM: genetically modified; $\mathrm{H}_{2} \mathrm{O}_{2}$ : hydrogen peroxide; $\mathrm{NO}$ : nitric oxide; XA: xanthurenic acid; CAs: carbonic anhydrase.

\section{Acknowledgments}

We thank Covenant University and Mr Jide Ayodele of CUBRe for the support they provided.

\section{Authors' contributions}

EOA, RK and EA conceptualized the manuscript. EOA and TB participated in the design. EOA sourced publications and wrote the manuscript. TB and YA contributed to the drafting of the manuscript. SF, OOO and RK revised and corrected the manuscript. SF, OOO, RK and EA participated in coordination. All authors read and approved the final manuscript.

\section{Funding}

Open Access funding enabled and organized by Projekt DEAL. The work was supported by the Deutsche Forschungsgemeinschaft (DFG) grant number KO 3678/5-1 and the Fogarty National Institutes of Health (NIH) Common Fund grant number 1U2RTW010679. The funding bodies did not play any role in the design of the study and collection, analysis and interpretation of data and in writing the manuscript.

\section{Availability of data and materials}

Not applicable.

\section{Ethics approval and consent to participate}

Not applicable.

\section{Consent for publication}

Not applicable.

\section{Competing interests}

The authors declare that they have no competing interests.

\section{Author details}

${ }^{1}$ Covenant University Bioinformatics Research (CUBRe), Covenant University, Ota, Ogun State, Nigeria. ${ }^{2}$ Department of Biochemistry, Covenant University, Ota, Ogun State, Nigeria. ${ }^{3}$ Department of Non-Communicable Disease Epidemiology, London School of Hygiene \& Tropical Medicine, Keppel St, Bloomsbury, London, UK. ${ }^{4}$ Integrated Research and Treatment Center, Center for Sepsis Control and Care (CSCC), Jena University Hospital, Am Klinikum 1, 07747 Jena, Germany. ${ }^{5}$ Computer and Information Sciences, Covenant University, Ota, Ogun State, Nigeria. ${ }^{6}$ Division of Applied Bioinformatics, German Cancer Research Center (DKFZ), G200, Im Neuenheimer Feld 280, 69120 Heidelberg, Germany.

Received: 18 March 2020 Accepted: 1 September 2020

Published online: 10 September 2020

\section{References}

1. WHO. World malaria report 2019. Geneva: World Health Organization; 2019.

2. Pimenta PFP, Orfano AS, Bahia AC, Duarte APM, Ríos-Velásquez CM, Melo FF, et al. An overview of malaria transmission from the perspective of Amazon Anopheles vectors. Mem Inst Oswaldo Cruz. 2015;110:23-47.

3. Sinka ME, Bangs MJ, Manguin S, Rubio-Palis Y, Chareonviriyaphap T, Coetzee $\mathrm{M}$, et al. A global map of dominant malaria vectors. Parasit Vectors. 2012;5:69.

4. Saraiva RG, Kang S, Simoes ML, Anglero-Rodriguez Yl, Dimopoulos G. Mosquito gut antiparasitic and antiviral immunity. Dev Comp Immunol. 2016:64:53-64.

5. Rono MK, Whitten MMA, Oulad-Abdelghani M, Levashina EA, Marois E. The major yolk protein vitellogenin interferes with the anti-plasmodium response in the malaria mosquito Anopheles gambiae. PLoS Biol. 2010;8:e1000434.

6. Spencer CS, Yunta C, de Lima GPG, Hemmings K, Lian LY, Lycett G, et al. Characterisation of Anopheles gambiae heme oxygenase and metalloporphyrin feeding suggests a potential role in reproduction. Insect Biochem Mol Biol. 2018;98:25-33.

7. Nelson DL, Lehninger AL, Cox MM. Lehninger principles of biochemistry. 4th ed. New York: W.H. Freeman; 2008.

8. Vizioli J, Catteruccia F, della Torre A, Reckmann I, Müller HM. Blood digestion in the malaria mosquito Anopheles gambiae: molecular cloning and biochemical characterization of two inducible chymotrypsins. Eur J Biochem. 2001;268:4027-35.

9. Prevot Gl, Laurent-Winter C, Rodhain F, Bourgouin C. Sex-specific and blood meal-induced proteins of Anopheles gambiae midguts: analysis by two-dimensional gel electrophoresis. Malar J. 2003;2:1.

10. Smith RC, Barillas-Mury C, Jacobs-Lorena M. Hemocyte differentiation mediates the mosquito late-phase immune response against Plasmodium in Anopheles gambiae. Proc Natl Acad Sci USA. 2015;112:E3412-20.

11. Carlier PR, Anderson TD, Wong DM, Hsu DC, Hartsel J, Ma M, et al. Towards a species-selective acetylcholinesterase inhibitor to control the mosquito vector of malaria, Anopheles gambiae. Chem Biol Interact. 2008:175:368-75.

12. West PA, Protopopoff N, Wright A, Kivaju Z, Tigererwa R, Mosha FW, et al. Indoor residual spraying in combination with insecticide-treated nets compared to insecticide-treated nets alone for protection against malaria: a cluster randomised trial in Tanzania. PLoS Med. 2014;11:e1001630.

13. Cibulskis RE, Alonso P, Aponte J, Aregawi M, Barrette A, Bergeron L, et al. Malaria: global progress 2000-2015 and future challenges. Infect Dis Poverty. 2016:5:61.

14. Schmidt M, Hrabcova V, Jun D, Kuca K, Musilek K. Vector control and insecticidal resistance in the African malaria mosquito Anopheles gambiae. Chem Res Toxicol. 2018;31:534-47.

15. WHO. Larval source management: a supplementary malaria vector control measure: an operational manual. Geneva: World Health Organization; 2013.

16. Choi L, Wilson A. Larviciding to control malaria. Cochrane Database Syst Rev. 2017;2017:CD012736.

17. Buah-Kwofie A, Humphries MS, Pillay L. Bioaccumulation and risk assessment of organochlorine pesticides in fish from a global 
biodiversity hotspot: iSimangaliso Wetland Park, South Africa. Sci Total Environ. 2018;621:273-81.

18. Cassereau J, Ferré M, Chevrollier A, Codron P, Verny C, Homedan C, et al. Neurotoxicity of insecticides. Curr Med Chem. 2017;24:2988-3001.

19. Thatheyus AJ, Selvam ADG. Synthetic pyrethroids: toxicity and biodegradation. Appl Ecol Environ Sci. 2013;1:33-6.

20. Adolfi A, Poulton B, Anthousi A, Macilwee S, Ranson H, Lycett GJ. Functional genetic validation of key genes conferring insecticide resistance in the major African malaria vector, Anopheles gambiae. Proc Natl Acad Sci USA. 2019;116:25764-72.

21. Ranson $\mathrm{H}$, Lissenden N. Insecticide resistance in African Anopheles mosquitoes: a worsening situation that needs urgent action to maintain malaria control. Trends Parasitol. 2016;32:187-96.

22. Mavridis K, Wipf N, Medves S, Erquiaga I, Müller P, Vontas J. Rapid multiplex gene expression assays for monitoring metabolic resistance in the major malaria vector Anopheles gambiae. Parasit Vectors. 2019;12:9.

23. Gleave K, Lissenden N, Richardson M, Choi L, Ranson H. Piperonyl butoxide (PBO) combined with pyrethroids in insecticide-treated nets to prevent malaria in Africa. Cochrane Database Syst Rev. 2018;11:CD012776.

24. Lu G, Traoré C, Meissner P, Kouyaté B, Kynast-Wolf G, Beiersmann C, et al. Safety of insecticide-treated mosquito nets for infants and their mothers: randomized controlled community trial in Burkina Faso. Malar J. 2015;14:527.

25. Cheung J, Mahmood A, Kalathur R, Liu L, Carlier PR. Structure of the G119S mutant acetylcholinesterase of the malaria vector Anopheles gambiae reveals basis of insecticide resistance. Structure. 2018;26:130-6.

26. Ffrench-Constant RH, Williamson MS, Davies TGE, Bass C. Ion channels as insecticide targets. J Neurogenet. 2016:30:163-77.

27. Field LM, Emyr Davies TG, O'Reilly AO, Williamson MS, Wallace BA. Voltage-gated sodium channels as targets for pyrethroid insecticides. Eur Biophys J. 2017:46:675-9.

28. Thapa S, Lv M, Xu H. Acetylcholinesterase: a primary target for drugs and insecticides. Mini Rev Med Chem. 2017;17:1665-76.

29. Engdahl C, Knutsson S, Fredriksson SÅ, Linusson A, Bucht G, Ekström F. Acetylcholinesterases from the disease vectors Aedes aegypti and Anopheles gambiae: functional characterization and comparisons with vertebrate orthologues. PLoS One. 2015;10:e0138598.

30. Colovic MB, Krstic DZ, Lazarevic-Pasti TD, Bondzic AM, Vasic VM. Acetylcholinesterase inhibitors: pharmacology and toxicology. Curr Neuropharmacol. 2013;11:315-35.

31. Knutsson S, Kindahl T, Engdahl C, Nikjoo D, Forsgren N, Kitur S, et al. $\mathrm{N}$-Aryl-N'-ethyleneaminothioureas effectively inhibit acetylcholinesterase 1 from disease-transmitting mosquitoes. Eur J Med Chem. 2017:134:415-27.

32. Weill M, Fort P, Berthomieu A, Dubois MP, Pasteur N, Raymond M. A novel acetylcholinesterase gene in mosquitoes codes for the insecticide target and is non-homologous to the ace gene Drosophila. Proc R Soc Lond B Biol Sci. 2002;269:2007-16.

33. Zhao $P$, Wang $Y$, Jiang H. Biochemical properties, expression profiles, and tissue localization of orthologous acetylcholinesterase-2 in the mosquito, Anopheles gambiae. Insect Biochem Mol Biol. 2013:43:260-71.

34. Lu Y, Park Y, Gao X, Zhang X, Yao J, Pang YP, et al. Cholinergic and noncholinergic functions of two acetylcholinesterase genes revealed by gene-silencing in Tribolium castaneum. Sci Rep. 2012;2:288.

35. Agossa FR, Padonou GG, Koukpo CZ, Zola-Sahossi J, Azondekon R, Akuoko OK, et al. Efficacy of a novel mode of action of an indoor residual spraying product, SumiShield ${ }^{\circledR} 50$ WG against susceptible and resistant populations of Anopheles gambiae (s.l.) in Benin, West Africa. Parasit Vectors. 2018;11:293.

36. Burkot TR, Farlow R, Min M, Espino E, Mnzava A, Russell TL. A global analysis of National Malaria Control Programme vector surveillance by elimination and control status in 2018. Malar J. 2019;18:399.

37. Namountougou M, Soma DD, Kientega M, Balboné M, Kaboré DPA, Drabo $\mathrm{S}$, et al. Insecticide resistance mechanisms in Anopheles gambiae complex populations from Burkina Faso, West Africa. Acta Trop. 2019;197:105054.
38. Rakotondranaivo T, Randriamanarivo SF, Tanjona MR, Vigan-Womas I, Randrianarivelojosia M, Ndiath MO. Evidence of insecticide resistance to pyrethroids and bendiocarb in Anopheles funestus from Tsararano, Marovoay district, Madagascar. Biomed Res Int. 2018;2018:5806179.

39. Gupta RC, Mukherjee IRM, Malik JK, Doss RB, Dettbarn WD, Milatovic D. Insecticides. In: Gupta RC, editor. Biomarkers in toxicology. 2nd ed. London: Academic Press; 2019. p. 455-75.

40. Mangas I, Estevez J, Vilanova E, França TCC. New insights on molecular interactions of organophosphorus pesticides with esterases. Toxicology. 2017;376:30-43.

41. Sievers F, Wilm A, Dineen D, Gibson TJ, Karplus K, Li W, et al. Fast, scalable generation of high-quality protein multiple sequence alignments using Clustal Omega. Mol Syst Biol. 2011;7:539.

42. Madeira F, Park YM, Lee J, Buso N, Gur T, Madhusoodanan N, et al. The EMBL-EBI search and sequence analysis tools APIs in 2019. Nucleic Acids Res. 2019;47:W636-41.

43. Franklin MC, Rudolph MJ, Ginter C, Cassidy MS, Cheung J. Structures of paraoxon-inhibited human acetylcholinesterase reveal perturbations of the acyl loop and the dimer interface. Proteins Struct Funct Bioinform. 2016;84:1246-56.

44. Han Q, Wong DM, Robinson H, Ding H, Lam PC, Totrov MM, et al. Crystal structure of acetylcholinesterase catalytic subunits of the malaria vector Anopheles gambiae. Insect Sci. 2017;25:721-4.

45. DeLano WL. PyMOL: an open-source molecular graphics tool. CCP4 Newslett Protein Crystallogr. 2002;40:82-92.

46. Abreu-Villaça Y, Levin ED. Developmental neurobehavioral neurotoxicity of insecticides. In: Slikker W, Paule M, Wang C, editors. Handbook of developmental neurotoxicology. 2nd ed. London: Academic Press; 2018. p. 453-66.

47. Engdahl C, Knutsson S, Ekström F, Linusson A. Discovery of selective inhibitors targeting acetylcholinesterase 1 from disease-transmitting mosquitoes. J Med Chem. 2016;59:9409-21.

48. Carlier PR, Chen QH, Verma A, Wong DM, Mutunga JM, Müller J, et al. Select $\beta$-and $\gamma$-branched 1-alkylpyrazol-4-yl methylcarbamates exhibit high selectivity for inhibition of Anopheles gambiae versus human acetylcholinesterase. Pestic Biochem Physiol. 2018;151:32-9.

49. Lu L, Qi Z, Li Q, Wu W. Validation of the target protein of insecticidal dihydroagarofuran sesquiterpene polyesters. Toxins (Basel). 2016;8:79.

50. Nunes RD, Romeiro NC, De Carvalho HT, Moreira JR, Sola-Penna M, SilvaNeto MAC, et al. Unique PFK regulatory property from some mosquito vectors of disease, and from Drosophila melanogaster. Parasit Vectors. 2016;9:107.

51. O'Flynn BG, Hawley AJ, Merkler DJ. Insect arylalkylamine N-acetyltransferases as potential targets for novel insecticide design. Biochem $\mathrm{Mol}$ Biol J. 2018:4:4.

52. Vullo D, Syrjänen L, Kuuslahti M, Parkkila S, Supuran CT. Anion inhibition studies of a beta carbonic anhydrase from the malaria mosquito Anopheles gambiae. J Enzyme Inhib Med Chem. 2018;33:359-63.

53. Douris V, Steinbach D, Panteleri R, Livadaras I, Pickett JA, Van Leeuwen T, et al. Resistance mutation conserved between insects and mites unravels the benzoylurea insecticide mode of action on chitin biosynthesis. Proc Natl Acad Sci USA. 2016;113:14692-7.

54. Grigoraki L, Puggioli A, Mavridis K, Douris V, Montanari M, Bellini R, et al. Striking diflubenzuron resistance in Culex pipiens, the prime vector of West Nile Virus. Sci Rep. 2017;7:11699.

55. Fontoura NG, Bellinato DF, Valle D, Lima JBP. The efficacy of a chitin synthesis inhibitor against field populations of organophosphate-resistant Aedes aegypti in Brazil. Mem Inst Oswaldo Cruz. 2012;107:387-95.

56. Zhang $X$, Yan ZhuK. Biochemical characterization of chitin synthase activity and inhibition in the African malaria mosquito, Anopheles gambiae. Insect Sci. 2013;20:158-66.

57. Zhang X, Zhang J, Zhu K. Chitosan/double-stranded RNA nanoparticlemediated RNA interference to silence chitin synthase genes through larval feeding in the African malaria mosquito (Anopheles gambiae). Insect Mol Biol. 2010;19:683-93.

58. Riveron JM, Watsenga F, Irving H, Irish SR, Wondji CS. High Plasmodium infection rate and reduced bed net efficacy in multiple insecticideresistant malaria vectors in Kinshasa, Democratic Republic of Congo. J Infect Dis. 2017;217:320-8. 
59. Ranson H, Jensen B, Wang X, Prapanthadara L, Hemingway J, Collins F. Genetic mapping of two loci affecting DDT resistance in the malaria vector Anopheles gambiae. Insect Mol Biol. 2000;9:499-507.

60. Curtis C, Lines J, Hill N. DDT resistance in An. gambiae s.s. from Zanzibar: mosquito studies at the London School of Hygiene and Tropical Medicine. Progr Rep. 1983;44:10-2.

61. Martinez-Torres D, Chandre F, Williamson M, Darriet F, Berge JB, Devonshire AL, et al. Molecular characterization of pyrethroid knockdown resistance (kdr) in the major malaria vector Anopheles gambiae s.s. Insect Mol Biol. 1998;7:179-84.

62. Prapanthadara L, Hemingway J, Ketterman A. Partial purification and characterization of glutathione S-transferases involved in DDT resistance from the mosquito Anopheles gambiae. Pestic Biochem Physiol. 1993:47:119-33.

63. Ranson H, N'guessan R, Lines J, Moiroux N, Nkuni Z, Corbel V. Pyrethroid resistance in African anopheline mosquitoes: what are the implications for malaria control? Trends Parasitol. 2011;27:91-8.

64. Corbel V, N'Guessan R. Distribution, mechanisms, impact and management of insecticide resistance in malaria vectors: a pragmatic review. In: Manguin S, editor. Anopheles mosquitoes—new insights into malaria vectors. Rijeka: InTech; 2013. p. 579-633.

65. Ingham VA, Anthousi A, Douris V, Harding NJ, Lycett G, Morris M, et al. A sensory appendage protein protects malaria vectors from pyrethroids. Nature. 2020:577:376-80.

66. Ingham VA, Pignatelli P, Moore JD, Wagstaff S, Ranson H. The transcription factor Maf-S regulates metabolic resistance to insecticides in the malaria vector Anopheles gambiae. BMC Genomics. 2017;18:669.

67. Panini M, Manicardi GC, Moores G, Mazzoni E. An overview of the main pathways of metabolic resistance in insects. Invertebrate Surviv J. 2016;13:326-35

68. Berenbaum MR, Johnson RM. Xenobiotic detoxification pathways in honey bees. Curr Opin Insect Sci. 2015;10:51-8.

69. Vogel H, Musser RO, de la Paz Celorio-Mancera M. Transcriptome responses in herbivorous insects towards host plant and toxin feeding. In: Roberts JA, editor. Annual plant reviews online. Hoboken: John Wiley and Sons Ltd; 2018. p. 197-233.

70. Hemingway J, Ranson $\mathrm{H}$. Insecticide resistance in insect vectors of human disease. Annu Rev Entomol. 2000;45:371-91.

71. Nardini L, Hunt RH, Dahan-Moss YL, Christie N, Christian RN, Coetzee $\mathrm{M}$, et al. Malaria vectors in the Democratic Republic of the Congo: the mechanisms that confer insecticide resistance in Anopheles gambiae and Anopheles funestus. Malar J. 2017;16:448.

72. Wu XM, Xu BY, Si FL, Li J, Yan ZT, Yan ZW, et al. Identification of carboxylesterase genes associated with pyrethroid resistance in the malaria vector Anopheles sinensis (Diptera: Culicidae). Pest Manage Sci. 2018:74:159-69.

73. Schenkman J, Greim H, Bolwell G. Cytochrome P450: handbook of experimental pharmacology. Berlin: Springer; 1994

74. Djouaka RF, Bakare AA, Coulibaly ON, Akogbeto MC, Ranson H, Hemingway J, et al. Expression of the cytochrome P450s, CYP6P3 and CYP6M2 are significantly elevated in multiple pyrethroid resistant populations of Anopheles gambiae s.s. from southern Benin and Nigeria. BMC Genomics. 2008:9:538.

75. Isaacs AT, Mawejje HD, Tomlinson S, Rigden DJ, Donnelly MJ. Genomewide transcriptional analyses in Anopheles mosquitoes reveal an unexpected association between salivary gland gene expression and insecticide resistance. BMC Genomics. 2018;19:225.

76. McLaughlin LA, Niazi U, Bibby J, David JP, Vontas J, Hemingway J, et al. Characterization of inhibitors and substrates of Anopheles gambiae CYP6Z2. Insect Mol Biol. 2008;17:125-35.

77. Vontas J, Grigoraki L, Morgan J, Tsakireli D, Fuseini G, Segura L, et al. Rapid selection of a pyrethroid metabolic enzyme CYP9K1 by operational malaria control activities. Proc Natl Acad Sci USA. 2018;115:4619-24.

78. Riveron JM, Ibrahim SS, Chanda E, Mzilahowa T, Cuamba N, Irving H, et al. The highly polymorphic CYP6M7 cytochrome P450 gene partners with the directionally selected CYP6P9a and CYP6P9b genes to expand the pyrethroid resistance front in the malaria vector Anopheles funestus in Africa. BMC Genomics. 2014;15:817.

79. Weedall GD, Mugenzi LMJ, Menze BD, Tchouakui M, Ibrahim SS, Amvongo-Adjia N, et al. A cytochrome P450 allele confers pyrethroid resistance on a major African malaria vector, reducing insecticidetreated bednet efficacy. Sci TransI Med. 2019;1 1:eaat7386.

80. Chambers JE, Meek EC, Chambers HW. The metabolism of organophosphorus insecticides. In: Krieger R, editor. Hayes' handbook of pesticide toxicology. 3rd ed. New York: Academic Press; 2010. p. 1399-407.

81. Forsyth CS, Chambers JE. Activation and degradation of the phosphorothionate insecticides parathion and EPN by rat brain. Biochem Pharmacol. 1989;38:1597-603.

82. Jan $\mathrm{YH}$, Richardson JR, Baker AA, Mishin V, Heck DE, Laskin DL, et al. Novel approaches to mitigating parathion toxicity: targeting cytochrome P450-mediated metabolism with menadione. Ann NY Acad Sci. 2016;1378:80-6.

83. Gunasekaran K, Muthukumaravel S, Sahu SS, Vijayakumar T, Jambulingam P. Glutathione S-transferase activity in Indian vectors of malaria: a defense mechanism against DDT. J Med Entomol. 2011;48:561-9.

84. Mitchell SN, Rigden DJ, Dowd AJ, Lu F, Wilding CS, Weetman D, et al. Metabolic and target-site mechanisms combine to confer strong DDT resistance in Anopheles gambiae. PLoS ONE. 2014;9:e92662.

85. Muthusamy M, Shivakumar S, Karthi K, Ramkumar R. Pesticide detoxifying mechanism in field population of Spodoptera litura (Lepidoptera: noctuidae) from South India. Egypt Acad J Biol Sci F Toxicol. 2011:3:51-7.

86. Vontas JG, Small GJ, Hemingway J. Glutathione S-transferases as antioxidant defence agents confer pyrethroid resistance in Nilaparvata lugens. Biochem J. 2001;357:65-72.

87. Wongsantichon J, Robinson RC, Ketterman AJ. Epsilon glutathione transferases possess a unique class-conserved subunit interface motif that directly interacts with glutathione in the active site. Biosci Rep. 2015;35:e00272.

88. Enayati AA, Ranson H, Hemingway J. Insect glutathione transferases and insecticide resistance. Insect Mol Biol. 2005;14:3-8.

89. Han JB, Li GQ, Wan PJ, Zhu TT, Meng QW. Identification of glutathione S-transferase genes in Leptinotarsa decemlineata and their expression patterns under stress of three insecticides. Pestic Biochem Physiol. 2016;133:26-34.

90. Toé $\mathrm{KH}$, N'Falé $\mathrm{S}$, Dabiré RK, Ranson $\mathrm{H}$, Jones $\mathrm{CM}$. The recent escalation in strength of pyrethroid resistance in Anopheles coluzzi in West Africa is linked to increased expression of multiple gene families. BMC Genomics. 2015;16:146.

91. Yahouedo GA, Chandre F, Rossignol M, Ginibre C, Balabanidou V, Mendez NGA, et al. Contributions of cuticle permeability and enzyme detoxification to pyrethroid resistance in the major malaria vector Anopheles gambiae. Sci Rep. 2017;7:11091.

92. Menze BD, Riveron JM, Ibrahim SS, Irving H, Antonio-Nkondjio C, Awono-Ambene $\mathrm{PH}$, et al. Multiple insecticide resistance in the malaria vector Anopheles funestus from northern Cameroon is mediated by metabolic resistance alongside potential target site insensitivity mutations. PLOS ONE. 2016;11:e0163261.

93. Riveron JM, Yunta C, Ibrahim SS, Djouaka R, Irving H, Menze BD, et al. A single mutation in the GSTe2 gene allows tracking of metabolically based insecticide resistance in a major malaria vector. Genome Biol. 2014;15:R27.

94. Pontes FJS, Maia RT, Lima MCP, Ayres CFJ, Soares TA. The role of the conformational dynamics of glutathione S-transferase epsilon class on insecticide resistance in Anopheles gambiae. J Braz Chem Soc. 2016;27:1602-15.

95. Wilding CS, Weetman D, Rippon E, Steen K, Mawejje H, Barsukov I, et al. Parallel evolution or purifying selection, not introgression, explains similarity in the pyrethroid detoxification linked GSTE4 of Anopheles gambiae and An. arabiensis. Mol Genet Genomics. 2015;290:201-15.

96. Cohuet A, Harris C, Robert V, Fontenille D. Evolutionary forces on Anopheles: what makes a malaria vector? Trends Parasitol. 2010;26:130-6.

97. Ndo C, Kopya E, Irving H, Wondji C. Exploring the impact of glutathione S-transferase (GST)-based metabolic resistance to insecticide on vector competence of Anopheles funestus for Plasmodium falciparum. Wellcome Open Res. 2019;4:52.

98. Minetti C, Ingham VA, Ranson $\mathrm{H}$. Effects of insecticide resistance and exposure on Plasmodium development in Anopheles mosquitoes. Curr Opin Insect Sci. 2020;39:42-9.

99. Prasad KM, Raghavendra K, Verma V, Velamuri PS, Pande V, et al. Esterases are responsible for malathion resistance in Anopheles stephensi: 
a proof using biochemical and insecticide inhibition studies. J Vector Borne Dis. 2017;54:226.

100. Main BJ, Everitt A, Cornel AJ, Hormozdiari F, Lanzaro GC. Genetic variation associated with increased insecticide resistance in the malaria mosquito, Anopheles coluzzii. Parasit Vectors. 2018;11:225.

101. Weetman D, Wilding CS, Neafsey DE, Müller P, Ochomo E, Isaacs AT, et al. Candidate-gene based GWAS identifies reproducible DNA markers for metabolic pyrethroid resistance from standing genetic variation in East African Anopheles gambiae. Sci Rep. 2018;8:2920.

102. Pignatelli P, Ingham VA, Balabanidou V, Vontas J, Lycett G, Ranson H. The Anopheles gambiae ATP-binding cassette transporter family: phylogenetic analysis and tissue localization provide clues on function and role in insecticide resistance. Insect Mol Biol. 2018;27:110-22.

103. Epis S, Porretta D, Mastrantonio V, Comandatore F, Sassera D, Rossi $P$, et al. $A B C$ transporters are involved in defense against permethrin insecticide in the malaria vector Anopheles stephensi. Parasit Vectors. 2014; $7: 349$

104. Mastrantonio V, Ferrari M, Epis S, Negri A, Scuccimarra G, Montagna $M$, et al. Gene expression modulation of $A B C$ transporter genes in response to permethrin in adults of the mosquito malaria vector Anopheles stephensi. Acta Trop. 2017;171:37-43.

105. Zhong D, Chang X, Zhou G, He Z, Fu F, Yan Z, et al. Relationship between knockdown resistance, metabolic detoxification and organismal resistance to pyrethroids in Anopheles sinensis. PLOS ONE. 2013;8:e55475.

106. Djogbenou L, Chandre F, Berthomieu A, Dabire R, Koffi A, Alout $H_{\text {, }}$ et al. Evidence of introgression of the ace-1R mutation and of the ace-1 duplication in West African Anopheles gambiae ss. PLoS ONE. 2008; $3: 2172$

107. Weill M, Malcolm C, Chandre F, Mogensen K, Berthomieu A, Marquine $M$, et al. The unique mutation in ace-1 giving high insecticide resistance is easily detectable in mosquito vectors. Insect Mol Biol. 2004;13:1-7.

108. Dabiré RK, Namountougou M, Diabaté A, Soma DD, Bado J, Toé HK, et al. Distribution and frequency of kdr mutations within Anopheles gambiae s.l. populations and first report of the ace.1 G119S mutation in Anopheles arabiensis from Burkina Faso (West Africa). PLoS ONE. 2014;9:e101484

109. Lol JC, Castañeda D, Mackenzie-Impoinvil L, Romero CG, Lenhart A, Padilla NR. Development of molecular assays to detect target-site mechanisms associated with insecticide resistance in malaria vectors from Latin America. Malar J. 2019;18:202.

110. Ibrahim SS, Ndula M, Riveron JM, Irving H, Wondji CS. The P450 CYP $6 Z 1$ confers carbamate/pyrethroid cross-resistance in a major African malaria vector beside a novel carbamate-insensitive N485I acetylcholinesterase-1 mutation. Mol Ecol. 2016;25:3436-52.

111. Assogba BS, Milesi P, Djogbénou LS, Berthomieu A, Makoundou P, BabaMoussa LS, et al. The ace-1 locus is amplified in all resistant Anopheles gambiae mosquitoes: fitness consequences of homogeneous and heterogeneous duplications. PLoS Biol. 2016;14:e2000618.

112. Djogbénou L, Labbé P, Chandre F, Pasteur N, Weill M. Ace-1 duplication in Anopheles gambiae: a challenge for malaria control. Malar J. 2009;8:70.

113. Wood O, Hanrahan S, Coetzee M, Koekemoer L, Brooke B. Cuticle thickening associated with pyrethroid resistance in the major malaria vector Anopheles funestus. Parasit Vectors. 2010;3:67.

114. Balabanidou V, Kampouraki A, MacLean M, Blomquist GJ, Tittiger C, Juarez MP, et al. Cytochrome P450 associated with insecticide resistance catalyzes cuticular hydrocarbon production in Anopheles gambiae. Proc Natl Acad Sci USA. 2016;113:9268-73.

115. Bass $C$, Jones $C M$. Mosquitoes boost body armor to resist insecticide attack. Proc Natl Acad Sci USA. 2016;113:9145-7.

116. Ingham VA, Jones CM, Pignatelli P, Balabanidou V, Vontas J, Wagstaff SC, et al. Dissecting the organ specificity of insecticide resistance candidate genes in Anopheles gambiae: known and novel candidate genes. BMC Genomics. 2014;15:1018.

117. Müller P, Warr E, Stevenson BJ, Pignatelli PM, Morgan JC, Steven A et al. Field-caught permethrin-resistant Anopheles gambiae overexpress CYP6P3, a P450 that metabolises pyrethroids. PLoS Genet. 2008;4:e1000286.

118. Zhou Y, Fu WB, Si FL, Yan ZT, Zhang YJ, He QY, et al. UDP-glycosyltransferase genes and their association and mutations associated with pyrethroid resistance in Anopheles sinensis (Diptera: Culicidae). Malar J. 2019;18:62.

119. Ye W, Zhang C, Xu N, Sun Y, Ma L, Shen B, et al. Carbonic anhydrase II confers resistance to deltamethrin in Culex pipiens pallens. Arch Insect Biochem Physiol. 2017;96:e21428.

120. Guo J, Xu Y, Yang $X$, Sun $X$, Sun $Y$, Zhou D, et al. TRE1 and CHS1 contribute to deltamethrin resistance in Culex pipiens pallens. Arch Insect Biochem Physiol. 2019;100:e21538.

121. Werling K, Shaw WR, Itoe MA, Westervelt KA, Marcenac P, Paton DG, et al. Steroid hormone function controls non-competitive Plasmodium development in Anopheles. Cell. 2019;177:315-25.

122. Nouzova M, Clifton ME, Noriega FG. Mosquito adaptations to hematophagia impact pathogen transmission. Curr Opin Insect Sci. 2019;34:21-6.

123. Whiten SR, Eggleston H, Adelman ZN. Ironing out the details: exploring the role of iron and heme in blood-sucking arthropods. Front Physiol. 2018;8:1134.

124. Cázares-Raga FE, Chávez-Munguía B, González-Calixto C, Ochoa-Franco AP, Gawinowicz MA, Rodríguez MH, et al. Morphological and proteomic characterization of midqut of the malaria vector Anopheles albimanus at early time after a blood feeding. J Proteomics. 2014;111:100-12.

125. Mongkol W, Nguitragool W, Sattabongkot J, Kubera A. Blood-induced differential gene expression in Anopheles dirus evaluated using RNA sequencing. Med Vet Entomol. 2018:32:399-406.

126. Villalon $\mathrm{JM}$, Ghosh $\mathrm{A}$, Jacobs-Lorena $\mathrm{M}$. The peritrophic matrix limits the rate of digestion in adult Anopheles stephensi and Aedes aegypti mosquitoes. J Insect Physiol. 2003:49:891-5.

127. Simões ML, Caragata EP, Dimopoulos G. Diverse host and restriction factors regulate mosquito-pathogen interactions. Trends Parasitol. 2018:34:603-16

128. Ribeiro JMC. A catalogue of Anopheles gambiae transcripts significantly more or less expressed following a blood meal. Insect Biochem Mol Biol. 2003;33:865-82.

129. Santiago PB, de Araújo CN, Motta FN, Praça YR, Charneau S, Bastos IMD, et al. Proteases of haematophagous arthropod vectors are involved in blood-feeding, yolk formation and immunity—a review. Parasit Vectors. 2017;10:79

130. Kumar M, Mohanty AK, Sreenivasamurthy SK, Dey G, Advani J, Pinto SM, et al. Response to blood meal in the fat body of Anopheles stephensi using quantitative proteomics: toward new vector control strategies against malaria. OMICS. 2017;21:520-30.

131. Billingsley PF, Hecker H. Blood digestion in the mosquito, Anopheles stephensi Liston (Diptera: Culicidae): activity and distribution of trypsin, aminopeptidase, and a-glucosidase in the midgut. J Med Entomol. 1991;28:865-71.

132. Dana AN, Hong YS, Kern MK, Hillenmeyer ME, Harker BW, Lobo NF, et al. Gene expression patterns associated with blood-feeding in the malaria mosquito Anopheles gambiae. BMC Genomics. 2005;6:5.

133. Billingsley PF. Blood digestion in the mosquito, Anopheles stephensi Liston (Diptera: Culicidae): partial characterization and post-feeding activity of midgut aminopeptidases. Arch Insect Biochem Physiol. 1990;15:149-63.

134. Vijay S, Rawal R, Kadian K, Singh J, AdakT, Sharma A. Proteome-wide analysis of Anopheles culicifacies mosquito midgut: new insights into the mechanism of refractoriness. BMC Genomics. 2018;19:337.

135. Baia-da-Silva DC, Alvarez LCS, Lizcano OV, Costa FTM, Lopes SCP, Orfanó $\mathrm{AS}$, et al. The role of the peritrophic matrix and red blood cell concentration in Plasmodium vivax infection of Anopheles aquasalis. Parasit Vectors. 2018;11:148.

136. Baton LA, Ranford-Cartwright LC. Ookinete destruction within the mosquito midgut lumen explains Anopheles albimanus refractoriness to Plasmodium falciparum (3D7A) oocyst infection. Int J Parasitol. 2012:42:249-58

137. Abraham EG, Jacobs-Lorena M. Mosquito midgut barriers to malaria parasite development. Insect Biochem Mol Biol. 2004;34:667-71.

138. Shahabuddin M, Toyoshima T, Aikawa M, Kaslow DC. Transmissionblocking activity of a chitinase inhibitor and activation of malarial parasite chitinase by mosquito protease. Proc Natl Acad Sci USA. 1993;90:4266-70 
139. Huber M, Cabib E, Miller LH. Malaria parasite chitinase and penetration of the mosquito peritrophic membrane. Proc Natl Acad Sci USA. 1991;88:2807-10.

140. Somboon P, Prapanthadara L. Trypsin and aminopeptidase activities in blood-fed females Anopheles dirus (Diptera: Culicidae) of differing susceptibility to Plasmodium yoelii nigeriensis. Southeast Asian J Trop Med Public Health. 2002;33:691-3.

141. Feldmann AM, Billingsley PF, Savelkoul E. Bloodmeal digestion by strains of Anopheles stephensi Liston (Diptera: Culicidae) of differing susceptibility to Plasmodium falciparum. Parasitology. 1990;101:193-200.

142. Shi Z, Zhi Z, Luo S, Chen B, He Z, et al. Molecular characterization and blood feeding-relative expression analysis of eight carboxypeptidase genes in Anopheles sinensis (Diptera: Culicidae). Acta Entomol Sin. 2017:60:621-31.

143. VenkatRao V, Kumar SK, Sridevi P, Muley VY, Chaitanya RK. Cloning, characterization and transmission blocking potential of midgut carboxypeptidase A in Anopheles stephensi. Acta Trop. 2017;168:21-8.

144. Marinotti O, Calvo E, Nguyen QK, Dissanayake S, Ribeiro JMC, James AA. Genome-wide analysis of gene expression in adult Anopheles gambiae. Insect Mol Biol. 2006;15:1-12.

145. Champion CJ, Xu J. Redox state affects fecundity and insecticide susceptibility in Anopheles gambiae. Sci Rep. 2018;8:13054.

146. Champion CJ, Kukutla P, Glennon EKK, Wang B, Luckhart S, Xu J. Anopheles gambiae: metabolomic profiles in sugar-fed, blood-fed, and Plasmodium falciparum-infected midgut. Dataset Papers Sci. 2017;2017:8091749.

147. Sterkel M, Oliveira JHM, Bottino-Rojas V, Paiva-Silva GO, Oliveira PL. The dose makes the poison: nutritional overload determines the life traits of blood-feeding arthropods. Trends Parasitol. 2017;33:633-44.

148. Capurro MDL, De Bianchi A, Marinotti O. Aedes aegypti lipophorin. Comp Biochem Physiol B. 1994;108:35-9.

149. Marinotti $O$, Nguyen QK, Calvo E, James AA, Ribeiro JMC. Microarray analysis of genes showing variable expression following a blood meal in Anopheles gambiae. Insect Mol Biol. 2005;14:365-73.

150. Thompson SN, Suarez RK. Metabolism. In: Resh VH, Cardé RT, editors. Encyclopedia of insects. 2nd ed. San Diego: Academic Press; 2009. p. 623-7.

151. Wegener G, Tschiedel V, Schlöder P, Ando O. The toxic and lethal effects of the trehalase inhibitor trehazolin in locusts are caused by hypoglycaemia. J Exp Biol. 2003;206:1233-40.

152. Kono Y, Takahashi M, Matsushita K, Nishina M, Kameda Y, Hori E. Inhibition of flight in Periplaneta americana (Linn.) by a trehalase inhibitor. Validoxylamine A. J Insect Physiol. 1994;40:455-61.

153. Scaraffia PY, Wells MA. Proline can be utilized as an energy substrate during flight of Aedes aegypti females. J Insect Physiol. 2003;49:591-601.

154. Giulivi C, Ross-Inta C, Horton AA, Luckhart S. Metabolic pathways in Anopheles stephensi mitochondria. Biochem J. 2008;415:309-16.

155. Gaviraghi A, Oliveira MF. A method for assessing mitochondrial physiology using mechanically permeabilized flight muscle of Aedes aegypti mosquitoes. Anal Biochem. 2019;576:33-41.

156. Marten AD, Stothard Al, Kalera K, Swarts BM, Conway MJ. Validamycin A delays development and prevents flight in Aedes aegypti (Diptera: Culicidae). J Med Entomol. 2020;57:1096-103.

157. Kumar S, Christophides GK, Cantera R, Charles B, Han YS, Meister $\mathrm{S}$, et al. The role of reactive oxygen species on Plasmodium melanotic encapsulation in Anopheles gambiae. Proc Natl Acad Sci USA. 2003;100:14139-44.

158. Molina-Cruz A, DeJong RJ, Charles B, Gupta L, Kumar S, JaramilloGutierrez G, et al. Reactive oxygen species modulate Anopheles gambiae immunity against bacteria and Plasmodium. J Biol Chem. 2008;283:3217-23.

159. Magalhaes T, Brackney DE, Beier JC, Foy BD. Silencing an Anopheles gambiae catalase and sulfhydryl oxidase increases mosquito mortality after a blood meal. Arch Insect Biochem Physiol. 2008;68:134-43.

160. Simões ML, Mlambo G, Tripathi A, Dong Y, Dimopoulos G. Immune regulation of Plasmodium is Anopheles species specific and infection intensity dependent. MBio. 2017;8:e01631-17.

161. Clayton AM, Dong Y, Dimopoulos G. The Anopheles innate immune system in the defense against malaria infection. J Innate Immun. 2014;6:169-81.
162. Yassine H, Osta MA. Anopheles gambiae innate immunity. Cell Microbiol. 2010;12:1-9.

163. Zakovic S, Levashina EA. NF-KB-like signaling pathway REL2 in immune defenses of the malaria vector Anopheles gambiae. Front Cell Infect Mi. 2017;7:258.

164. Levashina EA. Immune responses in Anopheles gambiae. Insect Biochem Mol Biol. 2004:34:673-8.

165. Oliveira JHM, Gonçalves RLS, Oliveira GA, Oliveira PL, Oliveira MF, Barillas-Mury C. Energy metabolism affects susceptibility of Anopheles gambiae mosquitoes to Plasmodium infection. Insect Biochem Mol Biol. 2011;41:349-55.

166. Goncalves RL, Oliveira JHM, Oliveira GA, Andersen JF, Oliveira MF, Oliveira PL, et al. Mitochondrial reactive oxygen species modulate mosquito susceptibility to Plasmodium infection. PLoS ONE. 2012;7:e41083.

167. Peterson TML, Gow AJ, Luckhart S. Nitric oxide metabolites induced in Anopheles stephensi control malaria parasite infection. Free Radic Biol Med. 2007;42:132-42.

168. Lanz-Mendoza H, Hernández-Martínez S, Ku-López M, del Carmen Rodríguez M, Herrera-Ortiz A, Rodríguez MH. Superoxide anion in Anopheles albimanus hemolymph and midgut is toxic to Plasmodium berghei ookinetes. J Parasitol. 2002;88:702-6.

169. de Almeida Oliveira G, Lieberman J, Barillas-Mury C. Epithelial nitration by a peroxidase/NOX5 system mediates mosquito antiplasmodial immunity. Science. 2012;335:856-9.

170. Kumar S, Gupta L, Han YS, Barillas-Mury C. Inducible peroxidases mediate nitration of Anopheles midgut cells undergoing apoptosis in response to Plasmodium invasion. J Biol Chem. 2004;279:53475-82.

171. Herrera-Ortiz A, Martínez-Barnetche J, Smit N, Rodriguez MH, LanzMendoza $\mathrm{H}$. The effect of nitric oxide and hydrogen peroxide in the activation of the systemic immune response of Anopheles albimanus infected with Plasmodium berghei. Dev Comp Immunol. 2011;35:44-50.

172. Luckhart S, Vodovotz Y, Cui L, Rosenberg R. The mosquito Anopheles stephensi limits malaria parasite development with inducible synthesis of nitric oxide. Proc Natl Acad Sci USA. 1998;95:5700-5.

173. Kajla M, Kakani P, Choudhury TP, Kumar V, Gupta K, Dhawan R, et al. Anopheles stephensi heme peroxidase HPX15 suppresses midgut immunity to support Plasmodium development. Front Immunol. 2017;8:249.

174. Nakhleh J, Christophides GK, Osta MA. The serine protease homolog CLIPA14 modulates the intensity of the immune response in the mosquito Anopheles gambiae. J Biol Chem. 2017;292:18217-26.

175. Barillas-Mury C. CLIP proteases and Plasmodium melanization in Anopheles gambiae. Trends Parasitol. 2007;23:297-9.

176. González-Santoyo I, Córdoba-Aguilar A. Phenoloxidase: a key component of the insect immune system. Entomol Exp Appl. 2012;142:1-16.

177. Liu K, Dong Y, Huang Y, Rasgon JL, Agre P. Impact of trehalose transporter knockdown on Anopheles gambiae stress adaptation and susceptibility to Plasmodium falciparum infection. Proc Natl Acad Sci USA. 2013;110:17504-9.

178. Liu K, Tsujimoto H, Huang Y, Rasgon JL, Agre P. Aquaglyceroporin function in the malaria mosquito Anopheles gambiae. Biol Cell. 2016;108:294-305.

179. Yamamoto DS, Sumitani M, Hatakeyama M, Matsuoka H. Malaria infectivity of xanthurenic acid-deficient anopheline mosquitoes produced by TALEN-mediated targeted mutagenesis. Transgenic Res. 2018:27:51-60.

180. Spring JH, Robichaux SR, Hamlin JA. The role of aquaporins in excretion in insects. J Exp Biol. 2009:212:358-62.

181. Kamareddine L, Nakhleh J, Osta MA. Functional interaction between apolipophorins and complement regulate the mosquito immune response to systemic infections. J Innate Immun. 2016;8:314-26.

182. Dhawan R, Gupta K, Kajla M, Kakani P, Choudhury TP, Kumar S, et al. Apolipophorin-III acts as a positive regulator of Plasmodium development in Anopheles stephensi. Front Physiol. 2017:8:185.

183. Hirai M, Kiuchi M, Wang J, Ishii A, Matsuoka H. cDNA cloning, functional expression and characterization of kynurenine 3-hydroxylase of Anopheles stephensi (Diptera: Culicidae). Insect Mol Biol. 2002;11:497-504.

184. Muhia DK, Swales CA, Deng W, Kelly JM, Baker DA. The gametocyteactivating factor xanthurenic acid stimulates an increase in membraneassociated guanylyl cyclase activity in the human malaria parasite Plasmodium falciparum. Mol Microbiol. 2001;42:553-60. 
185. Han Q, Beerntsen BT, Li J. The tryptophan oxidation pathway in mosquitoes with emphasis on xanthurenic acid biosynthesis. J Insect Physiol. 2007:53:254-63.

186. Hirai M, Arai M, Kawai S, Matsuoka H. PbGCß is essential for Plasmodium ookinete motility to invade midgut cell and for successful completion of parasite life cycle in mosquitoes. J Biochem. 2006;140:747-57.

187. Han Q, Robinson H, Gao YG, Vogelaar N, Wilson SR, Rizzi M, et al. Crystal structures of Aedes aegypti alanine glyoxylate aminotransferase. J Biol Chem. 2006:281:37175-82.

188. Rossi F, Garavaglia S, Giovenzana GB, Arcà B, Li J, Rizzi M. Crystal structure of the Anopheles gambiae 3-hydroxykynurenine transaminase. Proc Natl Acad Sci USA. 2006;103:5711-6.

189. Rossi F, Lombardo F, Paglino A, Cassani C, Miglio G, Arcà B, et al. Identification and biochemical characterization of the Anopheles gambiae 3-hydroxykynurenine transaminase. FEBS J. 2005;272:5653-62.

190. Canavesi R, Miggiano R, Stella M, Galli U, Rossi F, Rizzi M, et al. Study of Anopheles gambiae 3-hydroxykynurenine transaminase activity and inhibition by LC-MS/MS method. J Pharm Biomed Anal. 2019;173:154-61.

191. Maciel LG, Oliveira AA, Romão TP, Leal LL, Guido RV, Silva-Filha MHN, et al. Discovery of 1, 2,4-oxadiazole derivatives as a novel class of noncompetitive inhibitors of 3-hydroxykynurenine transaminase (HKT) from Aedes aegypti. Biorg Med Chem. 2020;28:115252.

192. Oliveira VS, Pimenteira C, da Silva-Alves DC, Leal LL, Neves-Filho RA, Navarro DM, et al. The enzyme 3-hydroxykynurenine transaminase as potential target for 1, 2, 4-oxadiazoles with larvicide activity against the dengue vector Aedes aegypti. Biorg Med Chem. 2013;21:6996-7003.

193. Chaverra-Rodriguez D, Macias VM, Hughes GL, Pujhari S, Suzuki Y, Peterson DR, et al. Targeted delivery of CRISPR-Cas9 ribonucleoprotein into arthropod ovaries for heritable germline gene editing. Nat Commun. 2018;9:3008.

194. Aryan A, Anderson MA, Myles KM, Adelman ZN. TALEN-based gene disruption in the dengue vector Aedes aegypti. PLoS ONE. 2013;8:e60082.

195. Berger D, Walters R, Gotthard K. What limits insect fecundity? Body size-and temperature-dependent egg maturation and oviposition in a butterfly. Funct Ecol. 2008;22:523-9.

196. Fuchs S, Behrends V, Bundy JG, Crisanti A, Nolan T. Phenylalanine metabolism regulates reproduction and parasite melanization in the malaria mosquito. PLOS ONE. 2014;9:e84865.

197. Kogan $\mathrm{PH}$, Hagedorn $\mathrm{HH}$. Polyamines, and effects from reducing their synthesis during egg development in the yellow fever mosquito, Aedes aegypti. J Insect Physiol. 2000;46:1079-95.

198. Simonet P, Gaget K, Parisot N, Duport G, Rey M, Febvay G, et al. Disruption of phenylalanine hydroxylase reduces adult lifespan and fecundity, and impairs embryonic development in parthenogenetic pea aphids. Sci Rep. 2016;6:34321.

199. Somani RR, Rai PR, Kandpile PS. Ornithine decarboxylase inhibition: a strategy to combat various diseases. Mini Rev Med Chem. 2018;18:1008-21.

200. Angleró-Rodríguez YI, Blumberg BJ, Dong Y, Sandiford SL, Pike A, Clayton AM, et al. A natural Anopheles-associated Penicillium chrysogenum enhances mosquito susceptibility to Plasmodium infection. Sci Rep. 2016:6:34084.

201. Graça-Souza AV, Maya-Monteiro C, Paiva-Silva GO, Braz GRC, Paes MC, Sorgine MHF, et al. Adaptations against heme toxicity in blood-feeding arthropods. Insect Biochem Mol Biol. 2006;36:322-35.

202. Gutteridge JM, Smith A. Antioxidant protection by haemopexin of haem-stimulated lipid peroxidation. Biochem J. 1988;256:861-5.

203. Zhou G, Kohlhepp P, Geiser D, Frasquillo MDC, Vazquez-Moreno L, Winzerling JJ. Fate of blood meal iron in mosquitoes. J Insect Physiol. 2007:53:1169-78.

204. DeJong RJ, Miller LM, Molina-Cruz A, Gupta L, Kumar S, Barillas-Mury C. Reactive oxygen species detoxification by catalase is a major determinant of fecundity in the mosquito Anopheles gambiae. Proc Natl Acad Sci USA. 2007;104:2121-6.

205. Nation JL Sr. Insect physiology and biochemistry. 3rd ed. Boca Raton: CRC Press; 2015

206. Adebiyi MO, Ogunlana OO, Adebiyi E, Fatumo S, Rasgon JL. The Anopheles gambiae insecticidal targets made bare by in-silica analysis. In: International conference on african development issues (CU-ICADI),
11-13 May 2015. African Leadership Development Centre, Covenant University Canaanland, Ota Ogun State, Nigeria; 2015.

207. Yousafi Q, Anwar H, Rashid H, Ali Q, Khan MS, Mehmood A, et al. Insecticide resistance management strategy for Aedes aegypti L. and Anopheles gambiae $\mathrm{G}$. through prediction of potential chorion peroxidase inhibitors using computer aided drug designing approach (CAAD). Pak J Agric Sci. 2019;56:675-86.

208. Supuran C. Carbonic anhydrases and metabolism. Metabolites. 2018;8:25.

209. Supuran CT. How many carbonic anhydrase inhibition mechanisms exist? J Enzyme Inhib Med Chem. 2016;31:345-60.

210. Syrjänen L, Vermelho AB, de Almeida Rodrigues I, Corte-Real S, Salonen T, Pan $\mathrm{P}$, et al. Cloning, characterization, and inhibition studies of a $\beta$-carbonic anhydrase from Leishmania donovani chagasi, the protozoan parasite responsible for leishmaniasis. J Med Chem. 2013;56:7372-81.

211. Angeli A, Pinteala M, Maier SS, Del Prete S, Capasso C, Simionescu $B C$, et al. Inhibition of $a_{-}, \beta-, \gamma^{-}, \delta-, \zeta$-and $\eta$-class carbonic anhydrases from bacteria, fungi, algae, diatoms and protozoans with famotidine. J Enzyme Inhib Med Chem. 2019;34:644-50.

212. Hiragaki S, Suzuki T, Mohamed AAM, Takeda M. Structures and functions of insect arylalkylamine $\mathrm{N}$-acetyltransferase (iaaNAT); a key enzyme for physiological and behavioral switch in arthropods. Front Physiol. 2015;6:113.

213. Han Q, Robinson H, Ding H, Christensen BM, Li J. Evolution of insect arylalkylamine $\mathrm{N}$-acetyltransferases: structural evidence from the yellow fever mosquito, Aedes aegypti. Proc Natl Acad Sci USA. 2012;109:11669-74.

214. O'Flynn BG, Suarez G, Hawley AJ, Merkler DJ. Insect arylalkylamine $\mathrm{N}$-acyltransferases: mechanism and role in fatty acid amide biosynthesis. Front Mol Biosci. 2018;5:66.

215. Long Y, Li J, Zhao T, Li G, Zhu Y. A new arylalkylamine N-acetyltransferase in silkworm (Bombyx mori) affects integument pigmentation. Appl Biochem Biotechnol. 2015;175:3447-57.

216. Noh MY, Koo B, Kramer KJ, Muthukrishnan S, Arakane Y. Arylalkylamine $\mathrm{N}$-acetyltransferase 1 gene (TCAANAT1) is required for cuticle morphology and pigmentation of the adult red flour beetle, Tribolium castaneum. Insect Biochem Mol Biol. 2016;79:119-29.

217. Muench SP, Rawson S, Eyraud V, Delmas AF, Da Silva P, Phillips C, et al. PA1b inhibitor binding to subunits $c$ and e of the vacuolar ATPase reveals its insecticidal mechanism. J Biol Chem. 2014;289:16399-408.

218. Gressent F, Duport G, Rahioui I, Pauchet Y, Bolland P, Specty O, et al. Biological activity and binding site characteristics of the PA1b entomotoxin on insects from different orders. J Insect Sci. 2007;7:12.

219. Gressent F, Da Silva P, Eyraud V, Karaki L, Royer C. Pea Albumin 1 subunit b (PA1b), a promising bioinsecticide of plant origin. Toxins (Basel). 2011:3:1502-17.

220. Gorecki L, Andrys R, Schmidt M, Kucera T, Psotka M, Svobodova B, et al. Cysteine-targeted insecticides against $A$. gambiae acetylcholinesterase are neither selective nor reversible inhibitors. ACS Med Chem Lett. 2019;11:65-71.

221. Pang YP, Ekström F, Polsinelli GA, Gao Y, Rana S, Hua DH, et al. Selective and irreversible inhibitors of mosquito acetylcholinesterases for controlling malaria and other mosquito-borne diseases. PLOS ONE. 2009;4:e6851.

222. Dou D, Park JG, Rana S, Madden BJ, Jiang H, Pang YP. Novel selective and irreversible mosquito acetylcholinesterase inhibitors for controlling malaria and other mosquito-borne diseases. Sci Rep. 2013;3:1068.

223. Alout $H$, Labbé $P$, Berthomieu A, Djogbénou L, Leonetti JP, Fort $P$, et al. Novel AChE inhibitors for sustainable insecticide resistance management. PLOS ONE. 2012;7:e47125.

224. Knutsson S, Engdahl C, Kumari R, Forsgren N, Lindgren C, Kindahl T, et al. Noncovalent inhibitors of mosquito acetylcholinesterase 1 with resistance-breaking potency. J Med Chem. 2018;61:10545-57.

225. Pennetier C, Costantini C, Corbel V, Licciardi S, Dabiré RK, Lapied B, et al. Mixture for controlling insecticide-resistant malaria vectors. Emerg Infect Dis. 2008;14:1707.

226. Camara S, Alou LPA, Koffi AA, Clegban YCM, Kabran J-P, Koffi FM, et al. Efficacy of Interceptor ${ }^{\circledR} \mathrm{G} 2$, a new long-lasting insecticidal net against wild pyrethroid-resistant Anopheles gambiae ss from Côte d'Ivoire: a semi-field trial. Parasite. 2018;25:42. 
227. Black BC, Hollingworth RM, Ahammadsahib KI, Kukel CD, Donovan S. Insecticidal action and mitochondrial uncoupling activity of AC-303,630 and related halogenated pyrroles. Pestic Biochem Physiol. 1994;50:115-28.

228. N'Guessan R, Ngufor C, Kudom AA, Boko P, Odjo A, Malone D, et al. Mosquito nets treated with a mixture of chlorfenapyr and alphacypermethrin control pyrethroid resistant Anopheles gambiae and Culex quinquefasciatus mosquitoes in West Africa. PLoS ONE. 2014;9:e87710.

229. Oumbouke WA, Koffi AA, Alou LPA, Rowland M, N'Guessan R. Evaluation of standard pyrethroid based LNs (MiraNet and MagNet) in experimental huts against pyrethroid resistant Anopheles gambiae s.l. M'bé, Côte d'Ivoire: potential for impact on vectorial capacity. PLoS ONE. 2019;14:e0215074.

230. N'Guessan R, Odjo A, Ngufor C, Malone D, Rowland M. A chlorfenapyr mixture net Interceptor ${ }^{\circledR} \mathrm{G} 2$ shows high efficacy and wash durability against resistant mosquitoes in West Africa. PLoS One. 2016;11:e0165925.

231. Oxborough RM, Kitau J, Matowo J, Feston E, Mndeme R, Mosha FW, et al. ITN mixtures of chlorfenapyr (pyrrole) and alphacypermethrin (pyrethroid) for control of pyrethroid resistant Anopheles arabiensis and Culex quinquefasciatus. PLoS ONE. 2013;8:e55781.

232. Oliver SV, Brooke BD. The role of oxidative stress in the longevity and insecticide resistance phenotype of the major malaria vectors Anopheles arabiensis and Anopheles funestus. PLOS ONE. 2016;11:e0151049.

233. Ketoh GK, Ahadji-Dabla KM, Chabi J, Amoudji AD, Apetogbo GY, Awokou F, et al. Efficacy of two PBO long lasting insecticidal nets against natural populations of Anopheles gambiae s.l. in experimental huts, Kolokopé. Togo. PLoS ONE. 2018;13:e0192492.

234. Birhanu A, Asale A, Yewhalaw D. Bio-efficacy and physical integrity of piperonylbutoxide coated combination net (PermaNet ${ }^{\circledR} 3.0$ ) against pyrethroid resistant population of Anopheles gambiae s.l. and Culex quinquefasciatus mosquitoes in Ethiopia. Malar J. 2019;18:224.

235. Corbel V, Chabi J, Dabiré RK, Etang J, Nwane P, Pigeon O, et al. Field efficacy of a new mosaic long-lasting mosquito net (PermaNet ${ }^{\circledR} 3.0$ ) against pyrethroid-resistant malaria vectors: a multi centre study in western and Central Africa. Malar J. 2010;9:113.

236. Awolola ST, Adeogun AO, Olojede JB, Oduola AO, Oyewole IO, Amajoh CN. Impact of PermaNet 3.0 on entomological indices in an area of pyrethroid resistant Anopheles gambiae in south-western Nigeria. Parasit Vectors. 2014;7:236

237. Pennetier C, Bouraima A, Chandre F, Piameu M, Etang J, Rossignol $M$, et al. Efficacy of Olyset ${ }^{\circledR}$ Plus, a new long-lasting insecticidal net incorporating permethrin and piperonil-butoxide against multiresistant malaria vectors. PLoS ONE. 2013;8:e75134.

238. Menze BD, Kouamo MF, Wondji MJ, Tchapga W, Tchoupo M, Kusimo $\mathrm{MO}$, et al. An experimental hut evaluation of PBO-based and pyrethroid-only nets against the malaria vector Anopheles funestus reveals a loss of bed nets efficacy associated with GSTe2 metabolic resistance. Genes. 2020;11:143.

239. Oumbouke WA, Rowland M, Koffi AA, Alou LP, Camara S, N'Guessan R. Evaluation of an alpha-cypermethrin+ PBO mixture long-lasting insecticidal net VEERALIN ${ }^{\circledR}$ LN against pyrethroid resistant Anopheles gambiae ss: an experimental hut trial in M'bé, central Côte d'Ivoire. Parasit Vectors. 2019;12:544.

240. Riveron JM, Huijben S, Tchapga W, Tchouakui M, Wondji MJ, Tchoupo M, et al. Escalation of pyrethroid resistance in the malaria vector Anopheles funestus induces a loss of efficacy of piperonyl butoxide-based insecticide-treated nets in Mozambique. J Infect Dis. 2019;220:467-75

241. Paton DG, Childs LM, Itoe MA, Holmdahl IE, Buckee CO, Catteruccia F. Exposing Anopheles mosquitoes to antimalarials blocks Plasmodium parasite transmission. Nature. 2019;567:239-43.

242. Atkinson SC, Armistead JS, Mathias DK, Sandeu MM, Tao D, BorhaniDizaji N, et al. The Anopheles-midgut APN1 structure reveals a new malaria transmission-blocking vaccine epitope. Nat Struct Mol Biol. 2015;22:532-9.

243. Sandeu MM, Abate L, Tchioffo MT, Bayibéki AN, Awono-Ambéné $\mathrm{PH}, \mathrm{Nsango} \mathrm{SE}$, et al. Impact of exposure to mosquito transmissionblocking antibodies on Plasmodium falciparum population genetic structure. Infect Genet Evol. 2016;45:138-44.
244. Christophides GK, Vlachou D, Kafatos FC. Comparative and functional genomics of the innate immune system in the malaria vector Anopheles gambiae. Immunol Rev. 2004;198:127-48.

245. Mitchell SN, Catteruccia F. Anopheline reproductive biology: impacts on vectorial capacity and potential avenues for malaria control. Cold Spring Harb Perspect Med. 2017;7:a025593.

246. Carballar-Lejarazú R, James AA. Population modification of Anopheline species to control malaria transmission. Pathog Glob Health. 2017;111:424-35.

247. Vijay S, Rawat M, Adak T, Dixit R, Nanda N, Srivastava H, et al. Parasite killing in malaria non-vector mosquito Anopheles culicifacies species B: implication of nitric oxide synthase upregulation. PLOS ONE. 2011;6:e18400.

248. Ito J, Ghosh A, Moreira LA, Wimmer EA, Jacobs-Lorena M. Transgenic anopheline mosquitoes impaired in transmission of a malaria parasite. Nature. 2002;417:452-5.

249. Dong Y, Das S, Cirimotich C, Souza-Neto JA, McLean KJ, Dimopoulos G. Engineered Anopheles immunity to Plasmodium infection. PLoS Pathog. 2011;7:e1002458.

250. Lombardo F, Nolan T, Lycett G, Lanfrancotti A, Stich N, Catteruccia F, et al. An Anopheles gambiae salivary gland promoter analysis in Drosophila melanogaster and Anopheles stephensi. Insect Mol Biol. 2005; 14:207-16.

251. Simões ML, Dong Y, Hammond A, Hall A, Crisanti A, Nolan T, et al. The Anopheles FBN9 immune factor mediates Plasmodium species-specific defense through transgenic fat body expression. Dev Comp Immunol. 2017;67:257-65.

252. Alphey L, Benedict M, Bellini R, Clark GG, Dame DA, Service MW, et al. Sterile-insect methods for control of mosquito-borne diseases: an analysis. Vector Borne Zoo Dis. 2010;10:295-311.

253. Yang C, Feng X, Liu N, Li M, Qiu X. Target-site mutations (AChE-G119S and $k d r$ ) in Guangxi Anopheles sinensis populations along the ChinaVietnam border. Parasit Vectors. 2019;12:77.

254. Essandoh J, Yawson AE, Weetman D. Acetylcholinesterase (Ace-1) target site mutation 1195 is strongly diagnostic of carbamate and organophosphate resistance in Anopheles gambiae s.s. and Anopheles coluzzii across southern Ghana. Malar J. 2013;12:404.

255. Djègbè I, Agossa FR, Jones CM, Poupardin R, Cornelie S, Akogbéto M, et al. Molecular characterization of DDT resistance in Anopheles gambiae from Benin. Parasit Vectors. 2014;7:409.

256. Tchigossou G, Djouaka R, Akoton R, Riveron JM, Irving H, Atoyebi S, et al. Molecular basis of permethrin and DDT resistance in an Anopheles funestus population from Benin. Parasit Vectors. 2018;11:602.

257. Yahouédo GA, Cornelie S, Djègbè I, Ahlonsou J, Aboubakar S, Soares C, et al. Dynamics of pyrethroid resistance in malaria vectors in southern Benin following a large scale implementation of vector control interventions. Parasit Vectors. 2016;9:385.

258. Stevenson BJ, Bibby J, Pignatelli P, Muangnoicharoen S, O'Neill PM, Lian LY, et al. Cytochrome P450 6M2 from the malaria vector Anopheles gambiae metabolizes pyrethroids: sequential metabolism of deltamethrin revealed. Insect Biochem Mol Biol. 2011;41:492-502.

259. Riveron JM, Ibrahim SS, Mulamba C, Djouaka R, Irving H, Wondji MJ, et al. Genome-wide transcription and functional analyses reveal heterogeneous molecular mechanisms driving pyrethroids resistance in the major malaria vector Anopheles funestus across Africa. G3 (Bethesda). 2017;7:1819-32.

260. Wondji CS, Irving H, Morgan J, Lobo NF, Collins FH, Hunt RH, et al. Two duplicated P450 genes are associated with pyrethroid resistance in Anopheles funestus, a major malaria vector. Genome Res. 2009;19:452-9.

261. Duangkaew P, Pethuan S, Kaewpa D, Boonsuepsakul S, Sarapusit S, Rongnoparut P. Characterization of mosquito CYP6P7 and CYP6AA3: differences in substrate preference and kinetic properties. Arch Insect Biochem Physiol. 2011;76:236-48.

262. Vontas J, David JP, Nikou D, Hemingway J, Christophides GK, Louis C, et al. Transcriptional analysis of insecticide resistance in Anopheles stephensi using cross-species microarray hybridization. Insect Mol Biol. 2007; 16:315-24.

263. Ibrahim SS, Riveron JM, Stott R, Irving H, Wondji CS. The cytochrome P450 CYP6P4 is responsible for the high pyrethroid resistance in knockdown resistance-free Anopheles arabiensis. Insect Biochem Mol Biol. 2016;68:23-32 
264. Nardini L, Christian RN, Coetzer N, Koekemoer LL. DDT and pyrethroid resistance in Anopheles arabiensis from South Africa. Parasit Vectors. 2013;6:229.

265. Zhou D, Liu X, Sun Y, Ma L, Shen B, Zhu C. Genomic analysis of detoxification supergene families in the mosquito Anopheles sinensis. PLoS One. 2015;10:e0143387.

266. Mackenzie-Impoinvil L, Weedall GD, Lol JC, Pinto J, Vizcaino L, Dzuris $\mathrm{N}$, et al. Contrasting patterns of gene expression indicate differing pyrethroid resistance mechanisms across the range of the New World malaria vector Anopheles albimanus. PLOS ONE. 2019;14:e210586.

267. Antonio-Nkondjio C, Poupardin R, Tene BF, Kopya E, Costantini C, Awono-Ambene $\mathrm{P}$, et al. Investigation of mechanisms of bendiocarb resistance in Anopheles gambiae populations from the city of Yaoundé, Cameroon. Malar J. 2016;15:424.

268. Edi CV, Djogbenou L, Jenkins AM, Regna K, Muskavitch MAT, Poupardin $\mathrm{R}$, et al. CYP6 P450 enzymes and ACE-1 duplication produce extreme and multiple insecticide resistance in the malaria mosquito Anopheles gambiae. PLoS Genet. 2014;10:e1004236.
269. Bayili K, N'do S, Namountougou M, Sanou R, Ouattara A, Dabiré RK, et al. Evaluation of efficacy of Interceptor ${ }^{\circledR} \mathrm{G} 2$, a long-lasting insecticide net coated with a mixture of chlorfenapyr and alpha-cypermethrin, against pyrethroid resistant Anopheles gambiae s/ in Burkina Faso. Malar J. 2017;16:190.

270. Menze BD, Wondji MJ, Tchapga W, Tchoupo M, Riveron JM, Wondji CS. Bionomics and insecticides resistance profiling of malaria vectors at a selected site for experimental hut trials in central Cameroon. Malar J. 2018;17:317.

271. Toe KH, Müller P, Badolo A, Traore A, Sagnon N, Dabiré RK, et al. Do bednets including piperonyl butoxide offer additional protection against populations of Anopheles gambiae s.l. that are highly resistant to pyrethroids? An experimental hut evaluation in Burkina Fasov. Med Vet Entomol. 2018;32:407-16.

\section{Publisher's Note}

Springer Nature remains neutral with regard to jurisdictional claims in published maps and institutional affiliations.
Ready to submit your research? Choose BMC and benefit from:

- fast, convenient online submission

- thorough peer review by experienced researchers in your field

- rapid publication on acceptance

- support for research data, including large and complex data types

- gold Open Access which fosters wider collaboration and increased citations

- maximum visibility for your research: over 100M website views per year

At BMC, research is always in progress.

Learn more biomedcentral.com/submissions 